\title{
Uruguay frente a la crisis en Siria de 2013. EI delicado equilibrio principista
}

Wilson Fernández Luzuriaga ${ }^{I}$

Resumen: Este trabajo analiza la posición de Uruguay en el conflicto internacional generado por la guerra civil en Siria durante 2013, año en el que la situación se agrava con la supuesta utilización de armas químicas por parte el gobierno constituido y los esbozos de una intervención liderada por Estados Unidos de América. Como consecuencia, la Cancillería se ve comprometida a dar respuestas sobre un conflicto lejano que interpela el rol histórico del país en la defensa de los grandes principios del Derecho Internacional. Incluso, esas respuestas debieron equilibrarse con las emanadas de la UNASUR, en tanto bloque político en dialéctica constante con el hegemón hemisférico. Con ese objetivo, en primer término, se aportan reflexiones provenientes de las Teorías de las Relaciones Internacionales y del Derecho Internacional Público sobre el atributo de la autonomía -en clave de soberanía- de los Estados nacionales con su derivación medular: el principio de no intervención en asuntos internos. Esta premisa westfaliana, fundacional de la concepción estadocéntrica del sistema internacional, convive hoy día con la legitimidad de la intervención extranjera por razones humanitarias. En segundo término, se analizan los tres comunicados oficiales emitidos por el Ministerio de Relaciones Exteriores que cubren las diferentes instancias del conflicto, así como la declaración de los presidentes de la UNASUR en el momento más dramático de las hostilidades. Los comunicados se analizan a partir del autor y de los destinatarios del mensaje y de los principios de Derecho Internacional invocados. Se concluye que el gobierno elabora sus respuestas acorde a la tradición nacional con el énfasis en la observancia a los derechos humanos fundamentales, propio de la izquierda uruguaya, y con la ponderación a los principios de solución de controversias y del multilateralismo de las Naciones Unidas. No obstante, en total coherencia con posiciones marcadas en 2012 desde el Consejo de Derechos Humanos de las Naciones Unidas sobre el conflicto, la Cancillería demuestra una leve tendencia a censurar al gobierno establecido.

Palabras clave: Uruguay, Siria, política exterior.

\section{Uruguay facing the 2013 Syrian crisis. The delicate balance of the principled policy}

\begin{abstract}
This paper analyzes the position of Uruguay in the international conflict over the civil war in Syria generated during 2013, the year in which the situation is aggravated by the alleged use of chemical weapons by the government constituted and the outlines of an intervention led by the United States of America. As a result, the Foreign Ministry is committed to provide answers about a distant conflict that challenges the historical role of the country in defense of the great principles of international law. Even those answers must be balanced with those arising from UNASUR as a political bloc in constant dialectic with the hemispheric hegemon. To that end, first, reflections from the Theories of International Relations and Public International Law on the attribute of sovereignty-autonomy-in key national states with their core bypass are provided: the principle of nonintervention in internal affairs. This Westphalian premise founding of the state-conception of the international
\end{abstract}


system, coexists today with the legitimacy of foreign intervention on humanitarian grounds. Second, the three communiques issued by the Ministry of Foreign Affairs covering the different instances of conflict and the declaration of presidents of UNASUR in the most dramatic moment hostilities are analyzed. The releases are analyzed from the author and the recipients of the message and the principles of international law invoked. It is concluded that the government makes its responses according to the national tradition with the emphasis on the observance of fundamental, own human rights of the Uruguayan left, and the weight to the principles of dispute resolution and multilateralism of the United Nations. However, in total coherence with positions marked in 2012 from the United Nations Human Rights Council on the conflict, the Foreign Ministry shows a slight tendency to censor the established government.

Keywords: Uruguay, Syria, Foreign Policy.

Artigo recebido em 01/04/2016 e aprovado em 07/04/2016.

\section{Introducción}

Este trabajo continúa con uno de los objetivos centrales y permanentes del Programa de Estudios Internacionales sobre seguimiento y análisis de la política exterior uruguaya. En lo que respecta a esta administración de gobierno (2010-2015), la tarea comenzó con las propias propuestas preelectorales de los partidos políticos uruguayos que en el año 2009 obtuvieron representación parlamentaria ${ }^{\mathrm{II}}$, inclusive con análisis sobre dichas plataformas y su inspiración en las tres tradiciones ideológicas nacionales, reconocidas consensualmente en materia de política exterior: la universalista o colorada, la blanca o resistente y la tercerista. ${ }^{\text {III }}$ En el año 2010, también se publicó un Documento de Trabajo referido al período de preparación e instalación del gobierno, desde la figura de José Mujica Cordano como presidente electo, en temas de política exterior. ${ }^{\text {IV }}$

Ya en 2011, se analizó la agenda internacional del Uruguay, en el primer año de esta administración de gobierno. ${ }^{V}$ Mientras que en el año 2012, se presentó un primer trabajo sobre la vigencia de las concepciones neorrealistas de las Relaciones Internacionales, para comprender y analizar la política exterior uruguaya contemporánea, desde los movimientos del gobierno de Mujica en 2009 y 2010. ${ }^{\text {VI }}$ No obstante, y siempre inserto en una tarea de seguimiento exhaustivo a la política exterior nacional, el análisis principal del año pasado, radicó en un incidente que confirmara los disensos nacionales en política exterior. En efecto, el trabajo consideró: las reacciones domésticas sobre la destitución del entonces Presidente de la República del Paraguay Fernando Lugo, las repercusiones por las posteriores sanciones colectivas en los marcos del MERCOSUR y la UNASUR al gobierno paraguayo, ya encabezado por Federico Franco, y el ingreso de Venezuela como Estado Parte en el MERCOSUR, aprovechando la suspensión paraguaya en el bloque regional. ${ }^{\text {VII }}$ 


\section{WILSON FERNÁNDEZ LUZURIAGA}

Este artículo, desde la evolución de distintos conceptos en sus dimensiones jurídicas y politológicas, analiza la posición del gobierno uruguayo en el conflicto internacional generado por la crisis interna en Siria en 2013, agravada con la supuesta utilización de armas químicas por el gobierno constituido y los esbozos de una intervención internacional liderada por Estados Unidos de América. Con ese objetivo, en primer término, se aportan reflexiones provenientes tanto de las Teorías de las Relaciones Internacionales como del Derecho Internacional Público, referidas a la autonomía -en clave de soberanía- de los Estados nacionales; su derivación más importante con el principio de no intervención en asuntos internos de los Estados nacionales -en tanto premisa fundacional de la concepción estadocéntrica del sistema internacional-, y la legitimidad de la intervención por razones humanitarias, incluyendo arriesgadas interpretaciones de la OTAN. En segundo término, se analizan los tres comunicados oficiales emitidos por el Ministerio de Relaciones Exteriores que cubren las diferentes instancias del conflicto, así como la declaración de los presidentes de la UNASUR, en el momento más dramático de las hostilidades con repercusiones y reacciones en todo el sistema internacional.

Dentro de la adscripción institucional de este trabajo explicitada en los primeros párrafos, cabe agregar que la recopilación de material estuvo facilitada por la tarea asidua del Observatorio de Política Exterior Uruguaya elaborado por el PEI en base a publicaciones de prensa y a los comunicados oficiales del Ministerio de Relaciones Exteriores. VIII

\section{Los nuevos límites de la autonomía estatal}

\section{I.1. La soberanía como atributo de los Estados nacionales}

La mayoría de los analistas coinciden en marcar el nacimiento de las relaciones internacionales con la Paz de Westfalia en 1648. Este tratado pone fin a la Guerra de los Treinta Años con readjudicaciones territoriales entre el Sacro Imperio Romano-Germánico, España, Francia, Países Bajos, Suecia y los principados alemanes. No obstante, su trascendencia deriva de la fundación de un nuevo orden internacional. En efecto, los pactos de 1648 consagran la concepción del Estado nacional, postergando dos reivindicaciones de jurisdicción: las relativas a concepciones feudales, hereditarias y/o patrimonialistas, y las derivadas de las pretensiones sobre una universalidad cristiana. A partir de la confirmación de un ejercicio exclusivo y excluyente de jurisdicción soberana de un gobierno sobre una población en un territorio determinado, se proclama la no injerencia de poderes -sean temporales o divinos- en los asuntos internos de ese Estado nacional. Como consecuencia, marca la capacidad de cada gobierno soberano para definir la religión en su dominio.

El jurista alemán Theodor Niemeyer ${ }^{\mathrm{IX}}$, no obstante, marcaba una cierta gradualidad en la aceptación universal del término soberanía.

\footnotetext{
Esta expresión [...] sirve desde el siglo XVII para designar un fin político consistente en la reunión de la mayor suma posible de poder político en una sola mano (ya abstracta: el Estado; ya concreta: el príncipe); pero más adelante recibió una nueva acepción científica y política, designándose con ella aquel órgano del Estado (sea una persona o una pluralidad de ellas o la reunión de varias comunidades) al que corresponden todas aquellas facultades del Estado no atribuidas por la Constitución a otros órganos, de modo que en este sentido significa soberanía la situación jurídica inherente, no precisamente a la mayor cantidad de poder, sino al poder supremo y decisivo del Estado.
} 
En definitiva, el autor se apoyaba en el viejo requisito de efectividad que el Derecho Internacional público le exige a un gobierno para ejercer la jurisdicción efectiva en sus dominios y obtener el reconocimiento internacional. Y todo basado en el también viejo postulado que una organización completa de una sociedad necesita reconocer qué persona o grupo de personas ha de decidir cuando fracasan todas las demás normas e instituciones ante un determinado conflicto.

Más allá de la gradualidad que advierte Niemeyer, la soberanía en su acepción westfaliana constituyó uno de los puntales de la estructura política internacional en los siglos XVII, XVIII, XIX y buena parte del XX. Este concepto es acogido por los primeros ilustrados ingleses, Thomas Hobbes y John Locke, en el siglo XVII, y posteriormente por los franceses del siglo XVIII, especialmente Jean-Jacques Rousseau, quien definitivamente, traslada la soberanía del monarca al pueblo, poniendo en manos del gobierno la tarea de implementar la voluntad popular ${ }^{\mathrm{X}}$.

También esta soberanía westfaliana fue el argumento de los países europeos colonialistas como forma de legitimación de dominios extracontinentales y hasta de abusos en los territorios conquistados, sin posibilidad de intervención extranjera. Incluso, la doctrina Monroe en 1823, responde con una noción de dominio, cuyo beneficiario es Estados Unidos de América, que relega a países extracontinentales de futuras reivindicaciones de soberanía en el continente. Ese mismo argumento sería utilizado en América Latina para desarrollar el principio de no intervención frente a toda potencia extranjera, inclusive de Estados Unidos de América. Los ejemplos más connotados lo constituyen las doctrinas Calvo, Drago y Tobar. ${ }^{\mathrm{XI}}$

Hasta la consagración de la Carta de las Naciones Unidas en 1945, el sistema westfaliano quedó compuesto, casi exclusivamente, por Estados independientes que se reconocían mutuamente autonomía jurídica. El sistema internacional se configuraba, efectivamente, por interacciones entre unidades nacionales jurídicamente sobernas, materializadas con alto grado de autonomía. Esas unidades nacionales aceptaban pocas obligaciones internacionales, confiaban en el equilibrio de poder y se consideraban con el derecho de recurrir al uso de la fuerza para solucionar sus conflictos. La confianza en el Derecho Internacional implicaba confianza en un sistema jurídico de coordinación que operaba más entre Estados que por encima de ellos. El liderazgo moral del presidente estadounidense Woodrow Wilson, con sus 14 puntos para la paz mundial, leídos ante el Congreso de su país en 1918, y el espíritu de los tratados celebrados en la Conferencia de Paz de París de 1919, con el Tratado de Versalles como instrumento medular y la creación de la Sociedad de Naciones, no generarían el anhelado espíritu multilateral ni pacifista.

Incluso, ese mismo escudo soberano, se utilizó por parte del fascismo y el nazismo en el siglo XX para justificar todo aquello que se hacía en nombre del la "voluntad del pueblo italiano" o el "sano espíritu del pueblo alemán". A tal punto que la alegación de los jerarcas nazis en los Juicios de Nuremberg fue su conducta ajustada al ordenamiento jurídico alemán vigente ${ }^{\mathrm{XII}}$.

La Segunda Guerra Mundial y estas violaciones a los derechos humanos en el eje nazifascista, se pueden imputar de causa inmediata y definitoria para que se esbozara un sistema supranacional, en este caso sobre protección internacional de los derechos humanos que ampare al ciudadano de abusos de los Estados, aún en órdenes jurídicos establecidos con algún grado de legitimidad. Surgen, así, ideas, más o menos difusas, de compromisos unilaterales de los Estados sin recompensas directas ni inmediatas, como: las normas

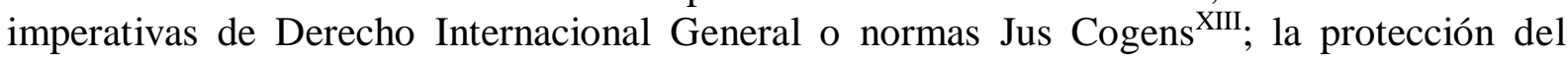
individuo frente a otros Estados y frente al suyo propio; la protección internacional del medio ambiente; las normas y los procesos de integración con vetas supranacionales. Esta concepción difusa sobre la pérdida de monopolio de los Estados nacionales como actores del 
sistema internacional, se traslada a la tensión entre el derecho de un país a la no intervención en sus asuntos internos y el derecho de la comunidad internacional a la intervención externa por bienes a tutelar, entre los que se incluyen asuntos de naturaleza humanitaria.

Más allá que paradigmas, escuelas de pensamiento o diversas concepciones teóricas se sigan afiliando a enfoques estadocéntricos del sistema internacional, las definiciones contemporáneas sobre las relaciones internacionales las consideran, genéricamente, como "interacciones humanas a través de fronteras nacionales y de los factores que afectan tales interacciones"XIV . De todas formas, si bien no se necesita de la intervención de los gobiernos nacionales para convertir las interacciones en relaciones internacionales, sólo a partir de la consolidación de los Estados nacionales podemos calificar como internacionales a esas interacciones. En otras palabras, las relaciones internacionales, se configuran a partir de la legitimidad atribuida a un gobierno central para que dentro de determinadas fronteras ejerza una jurisdicción legítima sobre la población.

\section{I.2. Concepto de autonomía en Relaciones Internacionales}

El internacionalista argentino Roberto Russell ${ }^{\mathrm{XV}}$, a partir de la construcción de un modelo de política exterior que denominara autonomía relacional, reseña y redefine el alcance del concepto de autonomía para el sistema internacional contemporáneo, integrando diferentes perspectivas disciplinarias. Justifica su esfuerzo, aseverando que, para la disciplina Relaciones Internacionales, la autonomía se considera como un propósito de la política exterior, común a todos los Estados nacionales. No obstante, ese propósito tiene un valor adicional para los países que no integran el grupo de las grandes potencias, ya que su posición sistémica supone grandes dificultades para satisfacer intereses y alcanzar metas.

El autor explica que el término autonomía ha sido empleado en la disciplina con una pluralidad de significados, de los que rescata tres acepciones diferentes. La primera entiende a la soberanía como uno de los dos principios, junto al de la territorialidad, del orden interestatal moderno, construido desde una concepción westfaliana, y supone el derecho de un gobierno a ser independiente de las demás estructuras de autoridad externas. Apelando al autor neorrealista Stephen Krasner ${ }^{\mathrm{XVI}}$, la autonomía como principio implica que "ningún actor externo goza de autoridad dentro de los límites del Estado". Por tanto, de este principio deriva la regla de no intervención en asuntos domésticos de los Estados nacionales, como se detallará, en este trabajo, cuando la autonomía se aborde desde el Derecho Internacional ${ }^{\mathrm{XVII}}$.

La segunda acepción ubica a la autonomía como condición del Estado nación que le posibilita fijar y alcanzar sus propias metas de manera independiente. Por tanto, es una propiedad que determinado Estado nacional puede tener o puede no tener. La autonomía como condición se mide en un continuo entre dos extremos ideales: la total dependencia y la completa autonomía. En el plano doméstico, un Estado goza de autonomía cuando fija metas que no reflejan simplemente las demandas de grupos particulares de su sociedad civil. Con igual significado, la autonomía externa caracteriza la capacidad y disposición de un Estado para tomar decisiones de acuerdo a sus necesidades y objetivos, así como para controlar efectos de procesos producidos fuera de fronteras, sin interferencias ni constreñimientos de otros actores internacionales. De aquí, se deriva que la autonomía es un asunto de grado, dependiendo, fundamentalmente, de los atributos de poder de un Estado determinado y de las condiciones externas ${ }^{\mathrm{XVIII}}$.

Por último, la tercera dimensión concibe a la autonomía como uno de los intereses nacionales de los Estados, junto a la supervivencia y el bienestar, los que pueden resumirse en tres términos: vida, libertad y propiedad. Aquí, el internacionalista argentino, se vale del autor constructivista Alexander Wendt ${ }^{X I X}$ para aseverar que, de alguna, forma los intereses 
mencionados son comunes a todos los Estados y no como meras guías normativas, sino como poderes causales que los predisponen a actuar de determinada manera. Así, la defensa y ampliación de la autonomía configura un patrón de actividad para todos los Estados, en la medida que quieren preservar su existencia, su libertad y reproducir sus condiciones materiales. Como consecuencia, cambios en el ámbito doméstico pueden llevar a los Estados a reformular el cariz del objetivo de la autonomía, aún ante las mismas presiones y oportunidades exógenas. De la misma manera, cambios en el sistema internacional, desde un orden conflictivo y fragmentado a uno cohesionado y cooperativo, tendrán consecuencias importantes en ese patrón de actividad ${ }^{\mathrm{XX}}$.

Dadas estas tres dimensiones, con el objetivo de evitar confusiones, Russell ${ }^{\mathrm{XXI}}$ propone reservar el concepto de soberanía para el ámbito jurídico y el de autonomía para el campo político. La noción de autonomía debe vincularse a la idea de autogobierno y control, en las dimensiones de condición e interés u objetivo nacional. En cambio, el significado de autonomía como principio o derecho incumbe a una imagen jurídica, en particular a la regla de no intervención en las estructuras de autoridad y en los asuntos internos de otros Estados. En síntesis: "Al reconocer la soberanía como un derecho, los Estados generan la expectativa compartida de no quitarse entre sí su vida, libertad y propiedad". Así, la soberanía es un requisito que antecede a la práctica de la autonomía. Ésta, a su vez, no es un derecho, sino una condición cambiante y un objetivo básico y permanente de las políticas exteriores nacionales.

En esta dirección, ya el fundador del neorrealismo, Kenneth Waltz, en su clásico libro Teoría de la Política Internacional, advertía sobre el error de identificar la soberanía de los Estados con su capacidad de hacer lo que deseen. En primer lugar, reafirma su concepción de un sistema internacional estadocéntrico, con los Estados como principales actores y caracterizados como unidades semejantes y autónomas, o sea soberanas. A partir de esta concepción, en segundo lugar, explica que los Estados nacionales pueden sufrir fuertes presiones y quedar obligados a actuar de determinada manera. La soberanía de los Estados jamás implicó que estén aislados de los efectos ejercidos por las acciones de otros Estados: "Ser soberano y ser dependiente no son situaciones contradictorias"XXII.

Entonces, ¿en qué términos queda definida la soberanía? Para Waltz ${ }^{\mathrm{XXIII}}$, la soberanía supone la capacidad de un Estado nacional para decidir, por sí solo, la forma de enfrentar sus problemas internos y externos. Y esto incluye la búsqueda de ayuda en otros Estados nacionales, ayuda que puede llegar a obtenerse asumiendo compromisos que limiten la libertad del peticionante. En definitiva, los Estados diseñan sus estrategias, definen sus rumbos y toman sus propias decisiones con el fin de satisfacer sus necesidades y deseos: "Decir que los Estados soberanos están siempre constreñidos no es más contradictorio que afirmar que los individuos libres con frecuencia toman decisiones bajo la presión de los acontecimientos".

Más allá de estas reducciones teóricas, la autonomía como soberanía ha sido con frecuencia desconocida con intervenciones de actores estatales e incluso no estatales que se valieron de una asimetría de poder y aprovecharon determinados contextos de vulnerabilidad del Estado nacional respectivo. Por otra parte, la propia comunidad internacional, en un proceso que se explicará en los siguientes apartados, comienza a aceptar objetivos más valiosos que la propia autonomía y que ameritan alguna forma de intervención. Russell ${ }^{\mathrm{XXIV}}$ cita como ejemplos la defensa de los derechos humanos, la promoción de la democracia, la protección del medio ambiente y el resguardo ante amenazas transnacionales.

\section{I.3. El principio de no intervención en el Derecho Internacional}




\section{WILSON FERNÁNDEZ LUZURIAGA}

Recogiendo los avances de las primeras décadas del siglo pasado, ya Niemeyer ${ }^{\mathrm{XV}}$ explicaba que para el Derecho Internacional, soberanía significa tanto ausencia de ciertas limitaciones como existencia de ciertas facultades positivas de un Estado con relación a los demás, bajo un pie de igualdad. Pero también conlleva la más alta competencia jurídica para la regulación de las relaciones internacionales. Esta alta competencia se comprueba, sustancialmente, con el derecho de celebrar tratados y el derecho de legación -capacidad y facultad de enviar y recibir agentes diplomáticos-.

La posición más aceptada sobre la naturaleza jurídica de este principio de no intervención, sobre todo en la doctrina clásica, lo ubica como corolario de los principios de independencia e igualdad soberana de los Estados. Por lo tanto, y como se adelantara, sus orígenes están en el propio proceso de formación de los Estados nacionales, en Europa, como una barrera frente a las pretensiones hegemónicas del Papado y del Imperio. No obstante, tuvo su consolidación en el continente americano. Y, finalmente, su consagración universal como deber de no intervención, en tanto principio de Derecho Internacional, se concreta recién en 1970 con la Declaración sobre los Principios de Derecho Internacional referentes a las relaciones de amistad y a la cooperación entre los Estados de conformidad con la Carta de las Naciones Unidas -Resolución 2625 (XXV)-. XXVI Por su alcance y valor intrínseco, se trata de un principio proclamado por los Estados pequeños contra la intromisión y la vocación hegemónica de los Estados más poderosos.

Para el jurista uruguayo, José María Gamio ${ }^{\text {XVII }}$, en Europa, la relativa paridad de poder militar entre las unidades nacionales y, más tarde, de éstas con relación a Estados Unidos de América, hizo poco factibles los actos de intervención. Cuando estos actos se concretaron, derivaron en conflictos de tal magnitud que absorbieron la ilicitud de la intervención original. En América Latina, la brecha de poder relativo entre sus Estados y los países europeos, primero, y Estados Unidos de América, más tarde, adquirió tal desproporción, que facilitó actos de intervención sin capacidad de respuesta.

Sobre los orígenes americanos del principio, el jurista uruguayo Alberto Domínguez Cámpora ${ }^{\mathrm{XVIII}}$ consideró al problema de la intervención como fundacional en las relaciones interamericanas, con intentos de consagración del principio de no intervención desde los países latinoamericanos y la resistencia de Estados Unidos de América. En primer lugar, define a la intervención como:

el acto por el cual un Estado interviene en los negocios internos o externos de otro, ejerciendo alguna clase de violencia que obliga al otro a aceptar de hecho soluciones extrañas en sus propios asuntos particulares y domésticos.

En segundo lugar, identifica tres momentos como paradigmáticos del problema. El primero con el Congreso de Jurisconsultos, Río de Janeiro de 1927, donde si bien se consagró el principio de no intervención con el voto de Estados Unidos de América, sólo comprendía los asuntos internos del otro Estado, dejándose afuera los asuntos externos. El segundo con la VI Conferencia Panamericana, La Habana 1928, en la que se presentaron tres posiciones y no se llegó a un consenso. XXIX El tercero con la VII Conferencia Panamericana, Montevideo 1933, con la sanción del principio de no intervención, tanto para asuntos internos como externos, en la Convención sobre Derechos y Deberes de los Estados ${ }^{\mathrm{XXX}}$.

No obstante, Estados Unidos de América estableció una reserva a esta disposición. Basada en el supuesto escaso tiempo para definir e interpretar sus términos, advirtió que no intervendría en asuntos internos de otros Estados, pero que no se ataría las manos con relación a los externos, fiel a la doctrina Monroe. El discurso de su representante Cordell Hull prometía ajustar la conducta de su país a los principios proclamados por el presidente Franklin 
D. Roosvelt, con relación a su política del buen vecino. Domínguez Cámpora ${ }^{\mathrm{XXI}}$ advertía sobre el peligro que el país del norte se arrogaba el derecho de interpretar si otro Estado no se comportaba como buen vecino, reservándose el derecho de intervención.

La primera consagración universal radica en el capítulo I de la Carta de las Naciones Unidas, que enumera "Propósitos y Principios", y establece en su artículo 2, parágrafo 7 que:

\begin{abstract}
Ninguna disposición de esta Carta autorizará a las Naciones Unidas a intervenir en los asuntos que son esencialmente de la jurisdicción interna de los Estados, ni obligará a los Miembros a someter dichos asuntos a procedimientos de arreglo conforme a la presente Carta; pero este principio no se opone a la aplicación de las medidas coercitivas prescritas en el capítulo VII.
\end{abstract}

La enumeración de los propósitos y principios, medular en esta sección dogmática del documento, constituye un conjunto de normas de conducta a observar por los Estados miembros y las reglas que regirán a la Organización. En ese rumbo, la propia Organización en la década del sesenta, se abocó a la elaboración de un documento que, finalmente, ratificó los siete principios fundamentales del Derecho Internacional surgidos de la Carta ${ }^{\text {XXII }}$ y codificó sus corolarios más importantes. La discusión particular del deber de no intervención fue de tal proporción que puede decirse que la Resolución 2625 es el instrumento que consagró su obligatoriedad.

El notable jurista uruguayo, Eduardo Jiménez de Aréchaga XXXIII explicó como, desde los inicios del debate en 1964, Estados Unidos de América, en tanto hegemón occidental y superpotencia en el contexto temporal de la llamada Guerra Fría, argumentó que no debía incluirse la no intervención como deber fundamental de los Estados nacionales. Para ello, el país del norte aducía tres argumentos. El primero consistía en que el artículo 2, parágrafo 7 , constituía una obligación de la ONU y no de sus países miembros. El segundo argumento radicaba en que la hipótesis de intervención de los Estados refería, únicamente al artículo 2 parágrafo 4 , sobre prohibición del uso y amenaza de la fuerza y, por tanto, ese deber no podía extenderse a normas de conducta en otros campos. XXXIV El tercero, reforzando el segundo argumento, sostenía que fuera del mencionado artículo 2 parágrafo 4 , los tratadistas no habían considerado de forma separada y expresa la hipótesis de intervención de los Estados.

No obstante, la opinión mayoritaria en el seno de la Organización defendió la pertinencia de la inclusión de este principio explicando, como primer argumento, que la Carta, al proclamar la igualdad soberana de los Estados, prohíbe la injerencia de un Estado en asuntos de otro:

El concepto jurídico de no intervención puede considerarse como dimanante del respeto a la personalidad y la independencia política del Estado, así como del principio de libre determinación, que comprende el derecho de los pueblos a elegir libremente sus propios sistemas político, económico, social y cultural ${ }^{\mathrm{XXXV}}$.

Como segundo argumento, se precisó que, si bien el artículo 2 parágrafo 7 hace referencia a la intervención de la Organización, la Carta no puede permitirle a los Estados hacer lo que le prohíbe a ésta, recordando que el acápite del mencionado artículo establece: "Para la realización de los Propósitos consignados en el artículo 1, la Organización y sus Miembros procederán de acuerdo con los siguientes Principios:"XXXVI.

Por otra parte, queda claro que la amenaza y el uso de la fuerza representa la forma más extrema de intervención y sobre la que más ha trabajado el Derecho Internacional, incluso desde la Carta de las Naciones Unidas con el artículo 2 parágrafo 4, el artículo 51 sobre el derecho inmanente de la legítima defensa -y el capítulo VII -sobre la acción del Consejo de Seguridad en caso de amenazas a la paz, quebrantamientos de la paz o actos de 


\title{
WILSON FERNÁNDEZ LUZURIAGA
}

agresión-. Pero de todas maneras, pueden configurarse otras formas de intervención en asuntos domésticos de un Estado que no impliquen la fuerza armada. Inclusive, la exclusión de la presión económica y política del concepto de uso de la fuerza hizo necesario consagrar como principio separado, el deber de los Estados de no interferir en asuntos de otros Estados.

En una clara reafirmación del aporte de la tradición americana al principio de no intervención, el texto de la Declaración 2625 reconoce, como fuente, los artículos de la Carta

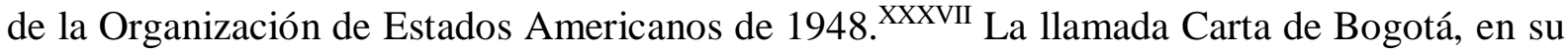
artículo 16, reafirma la jurisdicción de cada Estado sobre "habitantes, sean nacionales o extranjeros" dentro de los límites de su territorio, completando una faz interna del concepto de soberanía. Posteriormente, el artículo 17, consagra el derecho de cada Estado "a desenvolver libre y espontáneamente su vida cultural, política y económica", con el único límite de respetar "los derechos de la persona humana y los principios de la moral universal"; en otras palabras, consagra la faz externa del concepto de soberanía. La fórmula de la OEA, a la que remite la Declaración 2625, reproduce la concepción westfaliana en su más estricto alcance: sólo a partir de una reafirmación jurisdiccional de un gobierno central sobre la población en los límites territoriales preestablecidos, un Estado se proyecta hacia el sistema internacional con independencia política.

La Declaración 2625 comienza determinando que:

\begin{abstract}
Ningún Estado o grupo de Estados tiene derecho a intervenir directa o indirectamente, y sea cual fuere el motivo, en los asuntos internos o externos de cualquier otro. Por tanto, no solamente la intervención armada, sino también cualesquiera otras formas de injerencia o de amenaza atentatoria de la personalidad del Estado, o de los elementos políticos, económicos y culturales que lo constituyen, son violaciones del Derecho Internacional.
\end{abstract}

Jiménez de Aréchaga XXXVIII consideró un acierto haber incluido, y diferenciado, asuntos tanto de naturaleza doméstica como externa. En primer lugar, porque la historia revela incidentes sobre asuntos externos como el reconocimiento de un nuevo gobierno o el mantenimiento o ruptura de las relaciones diplomáticas con un Estado que, configurando una decisión estrictamente doméstica, han sido objeto de actos o de tentativas de intervención externa. En segundo lugar, porque existen asuntos internos que ya no pueden considerarse de estricta naturaleza doméstica, como el respeto y la observancia a los derechos humanos dentro de un Estado.

Paso seguido, en la Declaración, se describe la intervención por medio de ejemplos. En primer término, se alude a "aplicar o fomentar el uso de medidas económicas, políticas o de cualquier otra índole" que tengan como fin coaccionar a un Estado para que "subordine el ejercicio de sus derechos soberanos y obtener de él ventajas de cualquier orden". En segundo término, la asistencia - "organizar, apoyar, fomentar, financiar, instigar o tolerar"- a movimientos armados de naturaleza subversiva o terrorista que intenten cambiar el régimen en otro Estado así como la intervención en una guerra civil de otro Estado. En otras palabras, queda consagrada la proscripción al apoyo a estas fuerzas irregulares, aunque todavía no hayan concretado actos de fuerza, así como la proscripción de tomar protagonismo en una guerra civil, aún con acciones de naturaleza meramente política como un reconocimiento prematuro de beligerancia.

En definitiva, lo que permite calificar un acto como de interferencia ilegítima es su naturaleza coercitiva, sin necesidad de una intervención armada directa. Está claro que esto genera una línea divisoria delgada entre negociación y persuasión legítimas, y coerción y coacción violatorias del Derecho Internacional. Más allá del carácter lícito de cada acto concreto, en tanto elemento más trascendente e ineludible, el órgano internacional que deba 


\section{WILSON FERNÁNDEZ LUZURIAGA}

evaluar un incidente tendrá que valerse de ciertos principios generales como: el de la buena fe, subyacente en todas las relaciones entre sujetos de Derecho Internacional; el de buena vecindad, contemplado en el artículo 74 de la Carta de las Naciones Unidas, y el deber de los Estados de cooperar entre sí, definido en la propia Declaración $2625^{\mathrm{XXXIX}}$.

Finalmente, la Declaración reafirma la prohibición del uso de la fuerza con el fin de privar a los pueblos de su identidad nacional y el "derecho inalienable" a elegir su sistema político, económico, social y cultural, sin sufrir injerencias. Esta ampliación de la órbita de vigencia del principio, más allá de los Estados nacionales, debe interpretarse a la luz de la Declaración sobre la concesión de la independencia a pueblos y países coloniales Resolución 1514 (XV). ${ }^{\mathrm{XL}}$ La Declaración fue un llamamiento a la independencia de las colonias y se constituyó en un instrumento clave para los movimientos descolonizadores locales e internacionales. Además de establecer una conexión entre un dominio extranjero y la violación a los derechos humanos fundamentales de los dominados, declara el derecho de todos los pueblos a su libre determinación.

Y como párrafo final, desalentando una utilización del principio ajena al sistema de Naciones Unidas, la Declaración 2625 descarta toda aplicación futura del texto que afecte las disposiciones de la Carta "relativas al mantenimiento de la paz y la seguridad internacionales".

Gamio $^{\mathrm{XLI}}$ rescata doctrinas tendientes a establecer ciertas excepciones al principio de no intervención. La primera sostiene que sería válida la intervención por parte de un Estado para imponer el cumplimiento del deber de no intervención por parte de otro Estado. Al respecto, el fallo de la Corte Internacional de Justicia en el caso Nicaragua, ante la argumentación de Estados Unidos de América que el gobierno nicaragüense había concretado actos de intervención en países vecinos, afirmó que, de ser probadas las imputaciones, sólo justificarían contramedidas por parte del Estado víctima de esa intervención. Así, si el acto de intervención configura un ataque armado, la respuesta cabe en las normas sobre legítima defensa. Si no se trata de un ataque armado, las contramedidas deben, siguiendo el paralelismo con la hipótesis de legítima defensa, mantener la proporcionalidad en la respuesta.

La segunda afirma que la intervención en los asuntos de otro Estado sería legítima cuando tiende a amparar valores básicos, en general, los derechos humanos fundamentales. Así, se ha invocado tanto el derecho del Estado a intervenir para proteger a sus nacionales como para proteger los derechos humanos de los habitantes del Estado intervenido. No obstante, esta concepción encontraría plena coherencia si existiera un gobierno mundial. En su ausencia, la intervención queda en manos de otros Estados, normalmente los que tienen el poder de arrogarse las funciones de policía internacional para preservar o reestablecer determinados valores. La Corte Internacional de Justicia, también en el caso Nicaragua, rechazó actos de intervención con propósitos humanitarios, argumentando que la verificación y el respeto de los derechos humanos están asegurados por los tratados previstos y en vigor. Asimismo, si la intervención forma parte de un programa de ayuda humanitaria en una contienda civil de otro Estado y contempla sólo a los insurrectos, se vuelve a configurar una violación al principio ${ }^{\mathrm{XLII}}$.

La tercera excepción que se ha invocado apela al mantenimiento del equilibrio de poder o de no alineación con el adversario, invocado por parte de Estados Unidos de América en Cuba y en Nicaragua con el gobierno sandinista, y por parte de la Unión de Repúblicas Socialistas Soviéticas en Hungría en 1956, en Checoslovaquia en 1968 y en Afganistán en 1980. Al respecto, en el fallo de 1986, la Corte Internacional de Justicia afirmó que el Derecho Internacional no impide a ningún Estado dirigir su propia política exterior en forma coordinada con otros Estados, con prescindencia de la orientación política de éstos ${ }^{\mathrm{XLIII}}$. 
WILSON FERNÁNDEZ LUZURIAGA

También del punto de vista jurídico internacional parece vigente el concepto de Waltz sobre soberanía y dependencia como expresiones que no están, necesariamente, en contradicción, como se explicara en I.2.

\section{I.4. La intervención humanitaria en el Derecho Internacional}

Desde una visión que trasciende el campo estrictamente jurídico, Héctor Gros Espiell $^{\mathrm{XLIV}}$ afirmaba que una ponderada co-relación entre el deber de no intervención y una intervención legítima, debería revisar tanto el significado contemporáneo de la jurisdicción interna como el alcance de la soberanía estatal: la primera es la expresión de lo que va quedando momentáneamente como coto irreductible de la segunda. Recordaba que el principio de igualdad soberana de los Estados califica al poder etático, ejercido de acuerdo al Derecho Internacional y, en lo pertinente, de acuerdo al derecho interno en un ámbito espacial determinado. Por tanto, esta dinámica hace que:

La actual idea de lo que es la comunidad internacional, el aumento constante de las materias cuya regulación es vital para la vida de la humanidad en su conjunto y el cambio de las ideas respecto de cuáles son las cuestiones que no pueden ya estar reservadas exclusiva ni esencialmente a la jurisdicción interna de los Estados, ha llevado y seguirá llevando en el futuro al Derecho Internacional a ser competente y a regular asuntos que en un época anterior, estaban en el domino reservado a los Estados.

Bajo esta afirmación, el jurista uruguayo afirma que es indiscutible que la materia derechos humanos se convirtió en un tema no perteneciente al dominio reservado de los Estados nacionales. La afirmación la fundamenta tanto en el consenso de la doctrina como en la jurisprudencia de la Corte Internacional de Justicia, la Corte Europea de Derechos Humanos y la Corte Interamericana de Derechos Humanos. Inclusive, argumenta la existencia del derecho a la asistencia humanitaria -como derecho de tercera generación, individual y colectivo- que genera los deberes correlativos de no impedir dicha asistencia y, respetando el Derecho Internacional y las posibilidades materiales, de prestar suministrar o contribuir a brindar esa asistencia ${ }^{\mathrm{XLV}}$.

¿Cuáles son los límites que impone el Derecho Internacional a una intervención humanitaria? Para dar respuesta a esta interrogante, Gros Espiell ${ }^{\mathrm{XLVI}}$ advierte que reconocer la existencia del derecho a la asistencia humanitaria, no genera correlativamente un derecho y mucho menos un deber, de intervención alegando razones humanitarias, del que serían titulares terceros Estados, actuando individual o colectivamente. No obstante, la consagración de un derecho a la asistencia humanitaria necesita de una respuesta para que se concrete la posibilidad material de recibir esa asistencia, en otras palabras, para que se concrete un deber de acción humanitaria, como expresión de cooperación y solidaridad.

Esta fórmula imprecisa es clarificada por Gros Espiell ${ }^{\mathrm{XLVII}}$ sobre la base de estudios de diferentes doctrinos y de posiciones jurisprudenciales. Así, una intervención humanitaria legítima, en primer lugar, deberá constituir una ayuda estrictamente humanitaria que no responda a otras razones y que se ejerza con medios compatibles a su naturaleza y sin discriminar a los titulares del derecho a la asistencia. En segundo lugar, se fundará en el respeto del principio de igualdad soberana de los Estados, por lo que deberá ser solicitada o consentida por éstos, de manera tal que la soberanía, la integridad territorial y la unidad nacional no sean afectadas, y se obre en forma neutral e imparcial. En tercer lugar, y como consecuencia, la acción no podrá ser resultado de la voluntad de un Estado o de un grupo de 
Estados que actúen por fuera de las competencias de los organismos internacionales y quedará concertada en el marco de las atribuciones permitidas por el Derecho Internacional.

Esta enumeración de requisitos no despeja hipótesis de difícil dilucidación, tanto desde una dimensión estrictamente jurídica como desde una dimensión política, originadas en cuestionamientos sobre el ejercicio efectivo del poder. Al respecto, se pueden mencionar algunos escenarios de zonas grises como la disolución o desaparición de un Estado nacional o la inexistencia de un gobierno efectivo como para solicitar o admitir la asistencia humanitaria. Inclusive, pueden levantarse dudas significativas en la forma y los procedimientos de llevarla a cabo en cada situación particular.

En el reconocido Diccionario de Acción Humanitaria y Cooperación al Desarrollo de la Universidad del País Vasco, por intervención humanitaria se entiende aquellas:

Acciones emprendidas por la comunidad internacional en el territorio de un determinado Estado con el fin de proteger y defender a la población de violaciones graves y masivas de los derechos humanos fundamentales, y de garantizar la asistencia humanitaria a las víctimas de conflictos armados cuando el gobierno soberano impide su paso ${ }^{\mathrm{XLVIII}}$.

La naturaleza de la intervención incluye medidas que no conllevan el uso de la fuerza armada, como las acciones en el terreno político-diplomático, y medidas que refieren específicamente a las acciones armadas. ${ }^{\text {XIX }}$ De cualquier forma, los dos elementos definitorios consisten en su naturaleza coercitiva y en la inexistencia del consentimiento del Estado territorial. Por tanto, constituye una excepción a tres principios fundamentales del Derecho Internacional consagrados en la Carta de las Naciones Unidas: el de soberanía estatal, el de no intervención en los asuntos internos de otros Estados y el de la prohibición del uso o amenaza de la fuerza armada. Esta excepción, no prevista en la Carta, encuentra su justificación en una interpretación amplia de los supuestos del capítulo VII. No debe olvidarse la redacción del artículo 2 parágrafo 7 que, consagrando el principio de no intervención en la jurisdicción interna de los Estados, interpone como excepción la aplicación de las medidas coercitivas prescritas en dicho capítulo ${ }^{\mathrm{L}}$.

En definitiva, si la conducta de un Estado nacional cae en los supuestos de hacer peligrar la paz y la seguridad internacionales del capítulo VII -amenaza a la paz, quebrantamiento de la paz o actos de agresión-, el Consejo de Seguridad de las Naciones Unidas queda habilitado para activar excepciones a los principios de soberanía y no intervención, mediante medidas coercitivas que no impliquen el uso de la fuerza o medidas coercitivas que supongan acciones militares.

Con el fin de la Guerra Fría, el sistema de seguridad colectivo de la Carta experimenta dos cambios decisivos. El primero radica en el fin de la paralización del uso de la fuerza por parte del Consejo de Seguridad -motivada por el derecho al veto de los cinco miembros permanentes ${ }^{\mathrm{LI}}$ - en un contexto de superación de la rivalidad bipolar. El segundo cambio hace a la generalización y el afianzamiento de la interpretación que violaciones graves y sistemáticas de los derechos humanos fundamentales constituyen amenazas o quebrantamientos de la paz. Esto tiene su causa en la proliferación de tratados internacionales sobre derechos humanos y su aceptación universal, lo que directamente hace que su violación no pueda ser considerada como un asunto exclusivamente doméstico, sino atinente a la comunidad internacional. Los dos cambios decisivos, en definitiva, han ampliado las competencias del Consejo de Seguridad, inclusive con hipótesis en los parámetros del capítulo VII. Así, ha autorizado acciones coercitivas contra Estados con objeto de frenar las violaciones de derechos humanos en los casos de Somalia -1991-, la antigua Yugoslavia 1992- y Ruanda -1994 ${ }^{\text {LII }}$. 


\section{WILSON FERNÁNDEZ LUZURIAGA}

Pero también se han dado casos de intervenciones humanitarias unilaterales sin la autorización del Consejo de Seguridad. Los ejemplos más citados son la intervención de Israel en Uganda por el secuestro de un grupo de nacionales por parte de una organización palestina -1976-, la intervención de Estados Unidos de América en Granada para proteger conciudadanos que residían en ese país -1983- y la intervención de la OTAN en Kosovo para proteger a los albanos-kosovares del régimen del presidente servio Slobodan Milosevic -1999- La gran mayoría de la doctrina las califica de ilícitas. De todas formas, autores como Romualdo Bermejo (1993) y Jaime Oraá (1995) consideran su legitimidad siempre que se den las siguientes condiciones: existencia de una violación grave de los derechos humanos fundamentales; agotamiento de medios diplomáticos y de presión; proporcionalidad entre el uso de la fuerza y los objetivos perseguidos; carácter limitado de la operación en el tiempo y en el espacio; informe inmediato de la intervención al Consejo de Seguridad y, si se da el caso, al organismo regional pertinente ${ }^{\mathrm{LIII}}$.

En un contexto internacional que Abrisketa (2006) describe como de unipolar con un afianzamiento de Estados Unidos de América y un cierto relevamiento de la ONU, la autora describe, a modo de ejemplo sustantivo, el afianzamiento del intervencionismo unilateral por parte de la OTAN con la aprobación de su Nuevo Concepto Estratégico, Washington 1999. El documento, en primer lugar, transforma los fines de la Organización que dejan de ser meramente defensivos y asumen la misión especial de defender la seguridad y los valores democráticos dentro y fuera de sus fronteras, e incluye entre sus cometidos la lucha contra el genocidio, el terrorismo y las armas de destrucción masiva. En segundo lugar, redefine el ámbito de actuación, que ya no se circunscribe a los propios miembros de la Organización y circundantes, sino a una zona euroatlántica, que abarcaría gran parte del hemisferio norte, con espacios geográficos que Rusia considera de su influencia. En tercer lugar, alerta que la Organización se reserva el derecho de actuar sin el consentimiento expreso del Consejo de Seguridad, siempre que considere que no contradice la Carta de las Naciones Unidas ni las resoluciones de ese órgano.

Profundizando este nuevo rol, el Nuevo Concepto Estratégico de la OTAN, aprobado en Lisboa en 2010, amplía las hipótesis de amenazas para la OTAN: terrorismo; inestabilidad internacional; actividades ilegales trasnacionales; tráficos ilícitos de armas, seres humanos o drogas; ataques sobre el espacio cibernético, las líneas de comunicación y las infraestructuras críticas, entre otros. Asimismo, se identifican algunos factores como cambios tecnológicos, escasez de recursos, riesgos sanitarios y medio ambiente, como potenciales afectadores del planeamiento y las operaciones militares, pero no de los intereses vitales de los aliados. Las funciones básicas de la OTAN pasan a ser tres: defensa colectiva, gestión de crisis y seguridad cooperativa. Y en lo que refiere al capítulo VII de la Carta de las Naciones Unidas:

La antigua organización de defensa regional, mutando hacia un régimen de
seguridad global, actuará sin restricciones funcionales o geográficas, abordando
cualquier asunto o distancia que acuerden sus miembros. Esta tendencia cuestiona,
sin decirlo, el monopolio del Consejo de Seguridad de Naciones Unidas porque
acabará creando una alternativa al mismo, con menor legitimidad pero
probablemente con mayor eficacia. A medida que se consolide el giro, los aliados
podrán decidir si el foro de consultas prioritario para las grandes cuestiones de
seguridad global sigue siendo Naciones Unidas o la futura OTAN, una decisión que
corresponde a los aliados en función de cuál de las dos tenga mayor capacidad de
adaptación a los cambios y demuestre una mayor eficacia. (Arteaga, 2010: 6).

Un último punto y una discusión adicional, hacen a la legitimidad de la intervención por parte de un Estado para proteger a sus ciudadanos en otro Estado. Ya Niemeyer ${ }^{\text {LIV }}$ 
arriesgaba que el desarrollo del concepto jurídico de la ciudadanía -tanto en el Derecho Constitucional como, posteriormente, en el Derecho Internacional- trajo como consecuencia la extensión de la competencia del Estado fuera de sus fronteras territoriales. Esta extensión "diferente según los tratados y las prácticas y ambigua en la realidad" generó una especie de red en "todo el mundo civilizado, [que] pone ciertas cortapisas a la soberanía o dominio territorial absoluto".

La posición doctrinaria dominante sostiene que la intervención por esa causa, se encuadra más en hipótesis de legítima defensa que en hipótesis sobre intervención humanitaria. La idea sería considerar que la agresión a ciudadanos en el extranjero sería asimilable a un ataque armado al territorio del Estado, ya que los ciudadanos son un componente esencial del Estado nacional. No obstante, otros autores sostienen que estos casos siguen encuadrando en hipótesis de intervención humanitaria, ya que se trata de una figura que tiene como objetivo restablecer el respeto de los derechos humanos, y la nacionalidad de los afectados constituye un elemento irrelevante ${ }^{\mathrm{LV}}$.

\section{La política exterior uruguaya ante un nuevo desafío}

\section{II.1. Ministerio de Relaciones Exteriores (2/8/2013): "Comunicado sobre la situación humanitaria en Siria"}

El primer aspecto a destacar de los posicionamientos de la Cancillería uruguaya ante el conflicto en Sira, radica en que la preocupación original se centra en la dimensión humanitaria del conflicto. En efecto, el 2 de agosto, mediante un comunicado, el gobierno uruguayo manifiesta su preocupación por "la prolongada y grave crisis", apuntando a la pérdida de vidas humanas y el deterioro de las condiciones de vida. Lateralmente, y desde esta afectación, también se lamenta por los daños materiales al país y los aspectos históricoculturales, debido a la crítica situación en la histórica ciudad de Alepo que es patrimonio histórico de la humanidad.

Paso seguido, y apelando a una tradición nacional de respeto a los principios del Derecho Internacional, el comunicado cambia el sujeto de las oraciones que ya deja de ser el gobierno, para ser sustituido por Uruguay. En definitiva es el Estado nacional que "condena a la flagrante violación de los derechos humanos a los que ha sido sometida la población civil, actos contrarios al Derecho Internacional de los Derechos Humanos y del Derecho Humanitario". El texto, en una clara reafirmación del Derecho Internacional, no sólo alude específicamente a la disciplina en sí misma, sino a dos de sus principales ramas. ${ }^{\text {LVI }}$

También asumiendo como sujeto a Uruguay, se apela al multilateralismo como precepto, invocando a las Naciones Unidas y sus principios rectores en materia humanitaria y a la intervención reglada, solicitando el libre acceso a la "ayuda humanitaria internacional", particularmente con el ingreso de medicamentos y alimentos para la población civil. En este sentido, hay una exhortación a las partes a no impedir la asistencia, pero formulada en forma indirecta, sin mencionarlas. Esto, si bien no significa un desconocimiento de legitimidad al gobierno sirio, coloca a los rebeldes en una situación paritaria del punto de vista de los deberes con la propia población.

Reasumiendo el sujeto gobierno uruguayo, y la responsabilidad de esta Cancillería para este período de gobierno, se hace la solicitud concreta de solución pacífica para el conflicto por vías compatibles al respeto a los derechos humanos. Sin distinguir responsabilidades, ni imputar faltas a ninguno de los protagonistas de la contienda civil, nuevamente el gobierno hace "un llamado al inmediato cese de la violencia por ambas partes y a la mitigación de la crisis humanitaria en forma urgente y prioritaria". 


\section{II.2. Ministerio de Relaciones Exteriores (22/8/2013): "Comunicado"}

El comunicado de la Cancillería uruguaya, con la acusación generaliza en la comunidad internacional del uso de armas químicas por parte del gobierno sirio, hace una reiteración, en tanto "gobierno de la República Oriental del Uruguay", a la condena del uso de la violencia, utilizando la expresión "una vez más". Ratificando, también, su posición de imparcialidad, acusa a "las partes" de haber generado 60000 muertos y un número abrumador de heridos y desaparecidos, incluidos mujeres y niños. La mención específica de mujeres y niños, seguramente, busca poner en evidencia los ataques sufridos por la población civil.

Cambiando el sujeto del párrafo, es Uruguay quien condena el uso de armas químicas en tanto "acto de barbarie contrario a las normas del Derecho Internacional Humanitario y lesivo de los derechos inalienables de la población civil". Dado el contexto, la imputación queda radicada en el gobierno sirio. Cabe acotar que esta expresión textual es utilizada por Presidencia de la República para introducir el comunicado del Ministerio. Por otra parte, la Cancillería, nuevamente, alude a los objetos de estudio tanto del Derecho Internacional de los Derechos Humanos como del Derecho Internacional Humanitario.

En una expresión separada del punto de vista de la temática, aunque inserta en el párrafo anterior, se califica como "imprescindible que ambas partes aseguren un acceso sin restricciones de la ayuda humanitaria a todo el territorio sirio". Con esta breve frase, el comunicado, en primer lugar, reafirma la posición uruguaya sobre la validez de la intervención humanitaria. En segundo lugar, introduce un tono de advertencia sobre la necesidad de autorización para el ingreso de esa ayuda humanitaria. En tercer lugar, reconoce que, de hecho, la efectividad del gobierno sirio es contestada con eficacia por las fuerzas rebeldes, ya que se asume su potestad material de permitir -o de no permitir- el ingreso de la ayuda humanitaria.

Finalmente, y como al principio, es el sujeto gobierno uruguayo, quien asumiendo la responsabilidad de una alineación con "los demás países de la comunidad internacional", reclama el cese de fuego y la negociación para la solución pacífica del conflicto. En igual nivel, y también como gobierno, se respaldan los esfuerzos y mecanismos multilaterales de las Naciones Unidas.

\section{II.3. UNASUR (30/8/2013): "Declaración del Consejo de Jefas y Jefes de Estado y de Gobierno sobre la situación en la República Árabe de Siria"}

La declaración de los presidentes de la UNASUR, en Paramaribo, en la misma lógica que los comunicados de la Cancillería uruguaya, resalta la dimensión humanitaria del conflicto. Desde la "extrema preocupación" por el nuevo contexto, en el primero de sus cinco puntos, el órgano manifiesta "su hondo pesar por las irreparables perdidas de vidas humanas". También, en el primer punto y en la misma secuencia de los comunicados de Uruguay, alienta a la "solución pacífica y negociada" del conflicto. Pero adelanta, ante la amenaza de una intervención de terceros países liderados por Estados Unidos de América, que esa solución la debe encontrar "el pueblo sirio, en el ejercicio de su soberanía".

Desde esta reafirmación del principio de soberanía de los Estados, el documento, en su punto 2, no descartando el intervencionismo por razones humanitarias, sí: "Condena las intervenciones externas que sean incompatibles con la Carta de las Naciones Unidas". En otras palabras, la acción multilateral es indirectamente admitida y, como se explicó en I.3 y I.4, constituye la única forma de intervención que el Derecho Internacional admite, en estricta 
remisión al artículo 2 parágrafo 7, o sea como medida coercitiva en los parámetros del capítulo VII de la Carta. Y es la última frase de este punto 2 que, expresamente, "rechaza el desarrollo de estrategias intervencionistas de todo tipo".

A partir del tercer punto de la declaración, comienzan una serie de explicaciones, pero sin nuevas definiciones. Así, los presidentes hacen un llamamiento a la paz y a las soluciones jurídicas estrictas: "inmediato cese de la violencia" y "suspensión del suministro de todo tipo de armamento por parte de otros países hacia el territorio sirio", o sea hacia cualquiera de las dos partes. Paso seguido, piden el inicio de diálogo entre las partes e insisten en el respeto del Derecho Internacional Humanitario. Finalmente, reafirman su preferencia por una solución multilateral con "un llamado al Secretario General de las Naciones Unidas a mantener sus gestiones y profundizar sus esfuerzos [...]".

En esta misma lógica de explicación detallada, el cuarto punto también declara la confianza de los presidentes en el Representante Especial de la ONU/Liga Árabe, Lakdar Brahimi, y la necesidad de convocar a una conferencia internacional sobre el conflicto. El quinto punto califica de "crimen de guerra y de lesa humanidad" al uso de las armas químicas y pide que el episodio sea considerado "a la luz del Derecho Internacional" y que las partes se comporten "bajo el Derecho Internacional Humanitario", no enfocando la acusación exclusivamente hacia el gobierno sirio. Y, finalmente, el sexto punto, apelando al sistema de Naciones Unidas, exhorta a todas las partes a cooperar con la Misión de Investigación de las Naciones Unidas y urge al Consejo de Seguridad para que, respetando el informe, cumpla acciones para que cesen las agresiones y se proteja a la población, todo en el marco del Derecho Internacional, tal como lo establece la Carta.

\section{II.4. Ministerio de Relaciones Exteriores (16/9/2013): “Acuerdo sobre armas químicas alcanzado en Ginebra"}

El comunicado tiene el claro fin de celebrar el acuerdo del 14 de septiembre que posibilitó una salida negociada al tema puntual de la utilización de armas químicas en el conflicto de Siria y que, en definitiva, descartara una intervención extranjera. El único sujeto autor del mensaje es el gobierno uruguayo y aparece en cuatro de los seis párrafos. Así, en primer lugar, se "saluda el acuerdo alcanzado por los representantes de los Estados Unidos y Rusia", invocando el control internacional de los inspectores de la ONU y la posterior destrucción del arsenal. En otras palabras, apostando una vez más al multilateralismo y a la solución pacífica vía desarme.

En segundo término, se interpreta la aceptación de Siria, tanto de someter sus armas químicas al control internacional para su eliminación como de adherirse al Convenio internacional que prohíbe el uso de dichas armas ${ }^{\mathrm{LVII}}$, como pasos positivos para la solución pacífica del conflicto. Si bien se vuelve a poner un énfasis general en el principio de solución pacífica de controversias, llama la atención la expresión final del párrafo que instala una duda sobre las actitudes del gobierno sirio y acude al principio de la buena fe en el cumplimiento de las obligaciones internacionales. En concreto, el comunicado advierte que: "Para que este proceso pueda llevarse adelante es imprescindible que el gobierno sirio cumpla con los compromisos asumidos".

El gobierno uruguayo también envía mensajes al Consejo de Seguridad, "particularmente [a] sus miembros permanentes", para que asuman sus responsabilidades y logren una resolución que permita implementar el acuerdo. En ese sentido, se estampa un compromiso de apoyar a Estados Unidos de América y Rusia en la elaboración del proyecto de decisión a ser presentado ante el Consejo Ejecutivo de la Organización para la Prohibición de las Armas Químicas. Este párrafo es una nueva apuesta al multilateralismo, pero desde una 


\section{WILSON FERNÁNDEZ LUZURIAGA}

posición que muestra cierta disconformidad con el statu quo, referente al dominio de las grandes potencias en Naciones Unidas.

El último párrafo, encabezado otra vez por el gobierno del Uruguay, es una apelación a ambas partes a la paz - "cese inmediato de la violencia"-, a la solución pacífica de controversias y al respeto a los derechos fundamentales con: la autorización al "acceso irrestricto de la ayuda humanitaria", la protección a la población civil, y el respeto a "los derechos de las minorías religiosas".

\section{II.5. Cuadro de mensajes}

\begin{tabular}{|c|c|c|c|c|}
\hline Fecha & Contexto & Autor & Destinatario & Principio invocado \\
\hline \multirow[t]{6}{*}{ 02-Ago } & \multirow{6}{*}{$\begin{array}{l}\text { Preocupación unilateral } \\
\text { por lo prolongado del } \\
\text { conflicto }\end{array}$} & Gobierno & Contendientes & Respeto a los derechos humanos \\
\hline & & Uruguay & Contendientes & Respeto a los derechos humanos \\
\hline & & Uruguay & Contendientes & Multilateralismo \\
\hline & & Uruguay & Contendientes & Respeto a los derechos humanos \\
\hline & & Gobierno & Contendientes & $\begin{array}{l}\text { Solución pacífica de } \\
\text { controversias }\end{array}$ \\
\hline & & Gobierno & Contendientes & Respeto a los derechos humanos \\
\hline \multirow[t]{5}{*}{ 22-Ago } & \multirow{5}{*}{$\begin{array}{l}\text { Presunta utilización de } \\
\text { armas químicas del } \\
\text { gobierno sirio }\end{array}$} & Gobierno & Contendientes & Respeto a los derechos humanos \\
\hline & & Uruguay & Gobierno sirio & Respeto a los derechos humanos \\
\hline & & Uruguay & Contendientes & Intervención humanitaria \\
\hline & & Gobierno & Contendientes & $\begin{array}{l}\text { Solución pacífica de } \\
\text { controversias }\end{array}$ \\
\hline & & Gobierno & ONU & Multilateralismo \\
\hline \multirow[t]{3}{*}{ 30-Ago } & \multirow{3}{*}{$\begin{array}{c}\text { Amenaza de } \\
\text { intervención unilateral } \\
\text { de EEUU y aliados }\end{array}$} & $\begin{array}{l}\text { Presidentes } \\
\text { UNASUR }\end{array}$ & Contendientes & Respeto a los derechos humanos \\
\hline & & $\begin{array}{l}\text { Presidentes } \\
\text { UNASUR }\end{array}$ & Contendientes & $\begin{array}{l}\text { Solución pacífica de } \\
\text { controversias }\end{array}$ \\
\hline & & $\begin{array}{l}\text { Presidentes } \\
\text { UNASUR }\end{array}$ & $\begin{array}{l}\text { EEUU y } \\
\text { aliados }\end{array}$ & Soberanía y libre determinación \\
\hline
\end{tabular}


WILSON FERNÁNDEZ LUZURIAGA

\begin{tabular}{|c|c|c|c|c|}
\hline & & $\begin{array}{l}\text { Presidentes } \\
\text { UNASUR }\end{array}$ & $\begin{array}{l}\text { EEUU y } \\
\text { aliados }\end{array}$ & No intervención unilateral \\
\hline & & $\begin{array}{l}\text { Presidentes } \\
\text { UNASUR }\end{array}$ & $\begin{array}{l}\text { EEUU y } \\
\text { aliados }\end{array}$ & No intervención unilateral \\
\hline & & $\begin{array}{l}\text { Presidentes } \\
\text { UNASUR }\end{array}$ & ONU & Intervención humanitaria \\
\hline & & $\begin{array}{l}\text { Presidentes } \\
\text { UNASUR }\end{array}$ & Contendientes & $\begin{array}{l}\text { Solución pacífica de } \\
\text { controversias }\end{array}$ \\
\hline & & $\begin{array}{l}\text { Presidentes } \\
\text { UNASUR }\end{array}$ & $\begin{array}{c}\text { Terceros } \\
\text { países } \\
\text { involucrados }\end{array}$ & Soberanía y libre determinación \\
\hline & & $\begin{array}{l}\text { Presidentes } \\
\text { UNASUR }\end{array}$ & Contendientes & Respeto a los derechos humanos \\
\hline & & $\begin{array}{l}\text { Presidentes } \\
\text { UNASUR }\end{array}$ & ONU & Multilateralismo \\
\hline & & $\begin{array}{l}\text { Presidentes } \\
\text { UNASUR }\end{array}$ & ONU & Multilateralismo \\
\hline & & $\begin{array}{l}\text { Presidentes } \\
\text { UNASUR }\end{array}$ & Contendientes & Respeto a los derechos humanos \\
\hline & & $\begin{array}{l}\text { Presidentes } \\
\text { UNASUR }\end{array}$ & Contendientes & Multilateralismo \\
\hline & & $\begin{array}{l}\text { Presidentes } \\
\text { UNASUR }\end{array}$ & ONU & Multilateralismo \\
\hline \multirow[t]{5}{*}{ 16-Sep } & \multirow[t]{5}{*}{$\begin{array}{l}\text { Acuerdo sobre desarme } \\
\text { químico }\end{array}$} & Gobierno & $\begin{array}{c}\text { EEUU, Rusia } \\
\text { y ONU }\end{array}$ & Multilateralismo \\
\hline & & Gobierno & $\begin{array}{c}\text { EEUU, Rusia } \\
\text { y ONU }\end{array}$ & $\begin{array}{l}\text { Solución pacífica de } \\
\text { controversias }\end{array}$ \\
\hline & & Gobierno & $\begin{array}{l}\text { EEUU, Rusia } \\
\text { y ONU }\end{array}$ & Desarme \\
\hline & & Gobierno & Gobierno sirio & Desarme \\
\hline & & Gobierno & Gobierno sirio & $\begin{array}{l}\text { Solución pacífica de } \\
\text { controversias }\end{array}$ \\
\hline
\end{tabular}


WILSON FERNÁNDEZ LUZURIAGA

\begin{tabular}{|l|l|l|l|}
\hline \multirow{n}{*}{} & Gobierno & Gobierno sirio & Buena fe \\
\cline { 3 - 5 } & Gobierno & $\begin{array}{c}\text { Miembros } \\
\text { permanentes } \\
\text { (Consejo de } \\
\text { Seguridad) }\end{array}$ & Multilateralismo \\
\cline { 3 - 5 } & Gobierno & $\begin{array}{c}\text { EEUU y } \\
\text { Rusia }\end{array}$ & Multilateralismo \\
\cline { 3 - 5 } & Gobierno & $\begin{array}{c}\text { EEUU y } \\
\text { Rusia }\end{array}$ & Desarme \\
\cline { 3 - 5 } & Gobierno & Contendientes & $\begin{array}{l}\text { Solución pacífica de } \\
\text { controversias }\end{array}$ \\
\cline { 3 - 5 } & Gobierno & Contendientes & Respeto a los derechos humanos \\
\cline { 3 - 5 } & Gobierno & Contendientes & Intervención humanitaria \\
\hline
\end{tabular}

\section{II.6. Los mensajes en cifras}

Antes de hacer esta reseña cuantitativa de los mensajes, cabe aclarar que en el análisis de contenido de los párrafos anteriores, lo que define un mensaje, en cada comunicado, es el principio de Derecho Internacional imputado. Por lo tanto, en el apartado sobre los sujetos destinatarios, la suma de los porcentajes correspondientes no totaliza $100 \%$, ya que un autor puede invocar un principio de Derecho Internacional a más de un destinatario.

Los sujetos autores de los mensajes detectados son tres, pero deben analizarse desde dos universos diferentes. En lo que respecta a los comunicados nacionales, se advierte la elección de dos sujetos autores de mensajes: el gobierno uruguayo y el Estado nacional Uruguay. En cuanto al comunicado multilateral, el único sujeto que emite los mensajes es el cuerpo de presidentes de la UNASUR, en su Consejo de Jefas y Jefes de Estado y de Gobierno. En ese aspecto de los 37 mensajes decodificados, los 14 correspondientes a la UNASUR tienen como sujeto autor del mensaje a los presidentes de la UNASUR (100\%). En cuanto a los 23 mensajes de la Cancillería uruguaya, el 78\% tienen como autor al gobierno uruguayo, mientras el $22 \%$ son encabezados por el sujeto Uruguay.

Los destinatarios de los mensajes y los principios imputados se desagregan desde la suma de los tres comunicados que emite el Ministerio de Relaciones Exteriores uruguayo y la declaración del Consejo de Jefas y Jefes de Estado y de Gobierno de UNASUR. Esta suma puede ser cuestionada, ya que la voluntad del gobierno uruguayo expresada por su Cancillería es asimilada a la voluntad del gobierno uruguayo actuando en un foro multilateral, donde, obviamente, los textos aprobados requieren el consenso entre los participantes. No obstante, discriminar entre destinatarios y mensajes emitidos por la Cancillería y la UNASUR, sería un ejercicio estéril. En efecto, mientras la primera emite tres comunicados en contextos diferentes, la segunda se reúne y acuerda el texto en un escenario de agravamiento de la crisis 


\section{WILSON FERNÁNDEZ LUZURIAGA}

por la supuesta utilización de armas químicas del gobierno sirio y la amenaza de una intervención unilateral de Estados Unidos de América y sus aliados. De todas formas, en las conclusiones se reflexionará en base a cifras, pero tomando en cuenta las particularidades del contexto y de los sujetos autores y destinatarios de los mensajes, para evaluar el propio mensaje y su principio invocado.

En definitiva, el $49 \%$ de los mensajes son dirigidos a los dos contendientes sin distinción y el $11 \%$ al gobierno sirio. Asimismo, se registran como destinatarios a: Estados Unidos de América en el 22\% de los mensajes; la ONU en diferentes expresiones orgánicas en el 22\%; Rusia en el 14\%; aliados de Estados Unidos de América en las especulaciones sobre intervención unilateral en el 8\%; los miembros permanentes del Consejo de Seguridad de las Naciones Unidas, nominados genéricamente, en el 3\%; terceros países involucrados o con intenciones de involucrarse en el conflicto, en favor de uno de los contendientes, en el $3 \%$.

Finalmente, con relación a los ocho principios rectores del Derecho Internacional invocados, los mensajes dedican: el 27\% al respeto de los derechos humanos; el 24\% al multilateralismo; el $19 \%$ a la solución pacífica de las controversias internacionales; el $8 \%$ a la intervención humanitaria; el $8 \%$ al desarme; el 5\% al de soberanía y libre determinación; el 5\% al de no intervención unilateral contraria a la Carta de las Naciones Unidas; el 3\% al de buena fe en el cumplimiento de las obligaciones internacionales.

\section{Conclusiones}

Con la Paz de Westfalia, se dispara un concepto de soberanía estatal de aplicación bidimensional, cubriendo una faz interna, en el sentido de supremacía, y una faz externa en el sentido de independencia nacional. El corolario directo de esta consagración es el derecho de no intervención de los Estados nacionales en asuntos que son de su estricta naturaleza doméstica. Hasta finales de la Segunda Guerra Mundial, este principio fue desarrollado por políticos, pensadores y juristas. Incluso dio sustento, tanto a versiones colonialistas y expansionistas, como a argumentos de justificación o atenuación de violaciones de los derechos humanos. Desde entonces, y en esa dirección, los teóricos de las Relaciones Internacionales y los doctrinos del Derecho Internacional han trabajado en el alcance de concepciones, más o menos difusas, referentes a las normas imperativas de Derecho Internacional General, la protección internacional de los derechos humanos, la protección internacional del medio ambiente e, incluso, a normas y procesos de integración de alcance supranacional.

Así, desde las Relaciones Internacionales, Roberto Russell ${ }^{\mathrm{LVIII}}$ primero categorizó a la autonomía como principio, como condición y como interés nacional. Como principio, en el sentido que ningún actor externo goza de autoridad en esa jurisdicción estatal; como condición del Estado nación que le posibilita fijar y alcanzar sus metas de manera independiente, y como interés nacional común a todos los Estados, junto a la supervivencia y el bienestar. A partir de allí, propuso llamarle soberanía a la autonomía como principio y considerarla un requisito que antecede a la práctica de la autonomía como condición cambiante y como objetivo básico y permanente de las políticas exteriores nacionales. Finalmente, alertó sobre una comunidad internacional que comienza a aceptar objetivos más valiosos que la propia autonomía y que ameritan alguna forma de intervención.

Para el Derecho Internacional, el corolario de este principio de soberanía independencia e igualdad jurídica entre los Estados - es el principio de no intervención. La reseña de este Documento de Trabajo lo muestra como un desarrollo americano desde una dialéctica entre Estados Unidos de América y los países latinoamericanos. Pero, ante todo, lo 


\section{WILSON FERNÁNDEZ LUZURIAGA}

revela como un principio proclamado por los Estados pequeños contra la intromisión y la vocación hegemónica de los más poderosos. La Carta de las Naciones Unidas, la Declaración 2625 (XXV) y su remisión a la Carta de la Organización de Estados Americanos, así como los debates en los ámbitos panamericanos y universales, consagran el deber de no intervención aplicable a asuntos tanto de naturaleza doméstica como externa y materializado con acciones que impliquen el uso de la fuerza u otras formas coactivas. De la inclusión de los asuntos de naturaleza doméstica, deriva el ingreso a una especie de régimen de excepción con asuntos que ya no pueden considerarse de estricta naturaleza doméstica, como el respeto y la observancia a los derechos humanos dentro de un Estado.

Por otra parte, los juristas que trabajan las hipótesis legítimas o ilegítimas de intervención humanitaria al amparo del Derecho Internacional, parten de una afirmación casi consensual: la materia derechos humanos se convirtió en un tema no perteneciente al dominio reservado de los Estados nacionales. La afirmación se avala tanto en la doctrina como en la jurisprudencia de la Corte Internacional de Justicia, la Corte Europea de Derechos Humanos y la Corte Interamericana de Derechos Humanos.

La hipótesis de intervención legítima e incluso un derecho conexo a la asistencia humanitaria y un deber correlativo de no impedir dicha asistencia, sólo se configuraría bajo determinados supuestos. Gros Espiell ${ }^{\mathrm{LIX}}$, desde una visión clásica, resume esos supuestos en tres: naturaleza humanitaria y no discriminatoria de la intervención; solicitud o consentimiento de la unidad nacional involucrada; acción comprendida en las competencias de organismos internacionales y en el marco del Derecho Internacional. Las dudas pueden admitirse en materia de cuestionamientos sobre el ejercicio efectivo del poder en un Estado, envuelto en una contienda doméstica.

No obstante, visiones contemporáneas cuestionan el segundo supuesto e incluyen en la intervención humanitaria acciones tendientes a asegurar la asistencia a las víctimas de conflictos armados, cuando el gobierno soberano impide su paso, así como acciones coercitivas, impliquen o no el uso de la fuerza. Para configurar la intervención en estos términos, en tanto excepción a tres principios fundamentales del Derecho Internacional consagrados en la Carta de las Naciones Unidas -soberanía estatal, no intervención en los asuntos internos de otros Estados y prohibición del uso o amenaza de la fuerza armada- se debe recurrir a una interpretación amplia de los supuestos del capítulo VII sobre acción coercitiva del Consejo de Seguridad. Se invoca al artículo 2 parágrafo 7 que, consagrando el principio de no intervención, interpone como excepción la aplicación de las medidas coercitivas prescritas en dicho capítulo.

Los cambios devenidos con el fin de la Guerra Fría (etapa en la que estuvo paralizado el uso de la fuerza como sanción, debido al veto en el Consejo de Seguridad) y la convicción que violaciones a los derechos humanos pueden constituir una amenaza a la paz y seguridad internacionales, dieron como fruto autorizaciones de Naciones Unidas a intervenciones humanitarias. Pero también se verifican intervenciones unilaterales sin dicha autorización. Al respecto los dos documentos titulados Nuevo Concepto Estratégico de la OTAN, de 1999 y 2010, constituyen un intento de arrogación por Estados agrupados en un pacto militar, de intervenciones bajo contextos que sus integrantes califican como hipótesis de amenazas. Finalmente, siempre se ha discutido la legitimidad de la intervención humanitaria en defensa de nacionales afectados en un Estado extranjero. Aquí la argumentación más acorde al Derecho Internacional supone la asimilación de la respuesta con casos de legítima defensa y no con un escenario de intervención humanitaria.

La posición uruguaya en el grave conflicto civil de Siria, aparece como un nuevo desafío a una política exterior que debe responder a una tradición de defensa del Derecho Internacional. Tradicionalmente en Uruguay, ciertos acuerdos básicos sobre el rol del país en 


\section{WILSON FERNÁNDEZ LUZURIAGA}

el sistema internacional fueron elevados a la categoría de política exterior de Estado. Esos acuerdos básicos refieren esencialmente a principios o posturas, desde la asumida condición de país periférico: la imprescindible salvaguardia en el Derecho Internacional; la política de neutralidad y de asunción de roles de articulación ante conflictos internacionales; la política de un permanente equilibrio regional entre Argentina y Brasil; la solidaridad con los países limítrofes; la vocación nacional por la integración regional.

No obstante, tampoco el terreno estricto de los principios queda exento de tensiones. Basta cuestionarse sobre el mantenimiento de fuertes relaciones comerciales con todos los países del mundo, con independencia de su observancia a los derechos humanos; el principio de intervención en asuntos domésticos de otros Estados y su relación con la defensa de la democracia y la incorporación de cláusulas democráticas en procesos internacionales; la tensión entre la lucha contra el terrorismo y la respuesta en la legítima defensa preventiva, tesis sostenida por Estados Unidos de América y algunos de sus aliados sobre todo desde 2001.

En una primera instancia ( 2 de agosto), el Ministerio de Relaciones Exteriores uruguayo se dirige a la opinión pública, sin un hecho desencadenante específico, si bien el conflicto en Siria se exponía como prolongado y sumamente violento. Los otros tres comunicados, incluyendo el consensuado en la UNASUR, responden a instancias de agravamiento del conflicto con la presunta utilización de armas químicas del gobierno sirio (22 de agosto) y con la amenaza de intervención unilateral liderada por Estados Unidos de América (30 de agosto), o a instancias de distensión con el acuerdo sobre desearme químico propiciado por Estados Unidos de América y Rusia (16 de septiembre).

En cuanto a los autores de los mensajes, la Cancillería opta por utilizar en un $78 \%$ al sujeto gobierno y en sólo un $22 \%$ al sujeto Uruguay. Los mensajes no estampan evidencias para establecer una relación entre el sujeto elegido y los principios invocados. No obstante, cabe destacar que en el comunicado del 16 de septiembre, el único sujeto elegido es el gobierno uruguayo y aparecen, por primera vez, expresiones de desconfianza hacia el gobierno sirio, invocando el principio de buena fe, y críticas al sistema de seguridad colectiva de Naciones Unidas con mensajes a los miembros permanentes del Consejo de Seguridad.

Con relación a los destinatarios de los mensajes, se verifica una importante tendencia a dirigirlos a los contendientes sin distinción, marcada por el $49 \%$ de los mensajes. El 11\% de los mensajes dirigidos al gobierno sirio están comprendidos en su totalidad en dos de los tres comunicados emitidos por el Ministerio de Relaciones Exteriores, del 22 de agosto y del 16 de septiembre. Cabe recordar que Uruguay, en el ejercicio de la Presidencia del Consejo de Derechos Humanos de Naciones Unidas, durante 2012, tomó una actitud de dura condena al gobierno de Siria por crímenes contra la humanidad en el conflicto armado civil, enfrentándose a países del ALBA. ${ }^{\text {LX }}$

Estados Unidos de América aparece como destinatario en el $22 \%$ de los mensajes, a partir de los comunicados del 30 de agosto de la UNASUR y del 16 de septiembre del gobierno uruguayo. La concentración de mensajes en dos de las cuatro instancias hace a su participación a partir de la presunta utilización de armas químicas por el gobierno sirio. De todas maneras, y en concordancia con la evolución del conflicto, mientras la UNASUR le dirige mensajes en tonos de advertencia, el gobierno uruguayo tiende a saludar con beneplácito sus esfuerzos conjuntos con Rusia para el desarme. Rusia aparece como destinatario de un $14 \%$ de los mensajes de la Cancillería y todos concentrados en el comunicado del 16 de septiembre. A su vez, hay un $8 \%$ de mensajes de censuras a posibles aliados de Estados Unidos de América en una intervención unilateral concentrados en el comunicado de la UNASUR. Finalmente, y también en el comunicado de la UNASUR, hay 


\section{WILSON FERNÁNDEZ LUZURIAGA}

un mensaje dirigido a países con intenciones de involucrarse en el conflicto a favor de uno de los contendientes.

El otro gran destinatario es el sistema de Naciones Unidas que concentra también un $22 \%$ de los mensajes. Uruguay, el 22 de agosto, ya invoca a la Organización. Pero las Naciones Unidas son "reclamadas", definitivamente, con los comunicados de la UNASUR del 30 de agosto y de la Cancillería del 16 de septiembre. Mientras la UNASUR, invoca a la ONU, reafirmando una apuesta al multilateralismo y a la intervención humanitaria, Uruguay reclama roles que incluyen, también, desarme, solución pacífica de controversias e incluso, aunque sólo en un mensaje y dirigido puntualmente a los miembros permanentes del Consejo de Seguridad, observancia en el propósito de la seguridad colectiva.

Finalmente, en cuanto a los principios invocados, el respeto a los derechos humanos fundamentales acumula el $27 \%$ de los mensajes. Si bien los cuatro comunicados lo invocan, los dos primeros de la Cancillería uruguaya -2 de agosto y 22 de agosto- son emitidos por una preocupación estrictamente humanitaria. Incluso, cabe recordar que el primero de ellos es redactado sin un acontecimiento puntual de agravamiento del conflicto.

Tanto la invocación al multilateralismo como a la solución pacífica de controversias aparecen en guarismos parecidos con un 24 y un 19\%, respectivamente. Incluso al multilateralismo puede sumársele un $8 \%$ sobre la intervención humanitaria y un 5\% sobre el rechazo a la intervención unilateral contraria a la Carta de las Naciones Unidas. De la misma manera, al principio de solución pacífica de controversias puede adicionársele un $8 \%$ de los mensajes que invocan al desarme.

El principio de soberanía y libre determinación, sólo es invocado por la UNASUR en dos mensajes. Esto puede estar marcando la insistencia del bloque del ALBA en resguardar la jurisdicción del gobierno sirio. A contrario sensu, Uruguay invoca el principio de buena fe en el cumplimiento de las obligaciones internacionales en un mensaje del comunicado final del 16 de septiembre, de una manera precautoria, y sólo dirigido al gobierno sirio.

En suma, Uruguay se vio comprometido a dar respuesta a un conflicto lejano que ponía en tela de juicio su rol como histórico defensor de los grandes principios del Derecho Internacional y su posición en el concierto sudamericano de la UNASUR, en tanto bloque político en dialéctica constante con el hegemón continental, Estados Unidos de América. El gobierno da respuestas acordes a la tradición nacional. Incluso, la observancia a los derechos humanos fundamentales es, también, un principio enfatizado históricamente por la izquierda uruguaya. La ponderación a los principios de solución de controversias y de apego a las soluciones del multilateralismo de Naciones Unidas, también, responde a la tradición nacional y es bien consensuada en UNASUR. No obstante, en total coherencia con posiciones marcadas en 2012 desde el Consejo de Derechos Humanos de Naciones Unidas sobre el conflicto en Siria, la Cancillería demuestra una leve tendencia a censurar al gobierno establecido.

\footnotetext{
I Trabajo publicado, en diciembre de 2013, en la modalidad Serie Documentos de trabajo No 77. Montevideo: Unidad Multidisciplinaria de la Facultad de Ciencias Sociales, Universidad de la República.

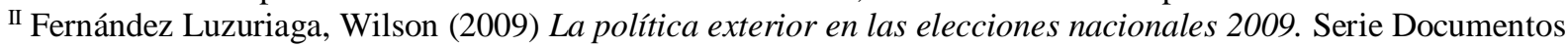
de Trabajo No 76. Montevideo: Unidad Multidisciplinaria de la Facultad de Ciencias Sociales, Universidad de la República.

III Fernández Luzuriaga, Wilson y Hernández Nilson, Diego (2010) “Tradiciones ideológicas de política exterior en las propuestas preelectorales 2009 de los partidos políticos uruguayos" en 3er. Congreso Uruguayo de
} 


\section{WILSON FERNÁNDEZ LUZURIAGA}

Ciencia Política. Uruguay: desde el cambio a la continuidad. Montevideo: Asociación Uruguaya de Ciencia Política (AUCIP). CD-Rom.

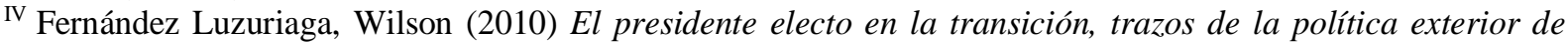
José Mujica. Serie Documentos de Trabajo No 78. Montevideo: Unidad Multidisciplinaria de la Facultad de Ciencias Sociales, Universidad de la República.

${ }^{\mathrm{V}}$ Fernández Luzuriaga, Wilson (2011) La agenda internacional del Uruguay en el primer año del gobierno de José Mujica. Serie Documentos de Trabajo No 79. Montevideo: Unidad Multidisciplinaria de la Facultad de Ciencias Sociales, Universidad de la República.

VI Fernández Luzuriaga, Wilson (2012) "La inserción internacional de Uruguay: una mirada desde las concepciones neorrealistas de las Relaciones Internacionales". (Citado en la Bibliografía).

${ }^{\mathrm{VII}}$ Fernández Luzuriaga, Wilson (2012) La política exterior uruguaya en 2012: treinta y seis días que ratificaron sus disensos. Serie Documentos de Trabajo No 80. Montevideo: Unidad Multidisciplinaria de la Facultad de Ciencias Sociales, Universidad de la República.

VIII Responsable del Observatorio: Diego Hernández Nilson.

IX Niemeyer, Theodor (1925). Derecho Internacional Público. Barcelona - Buenos Aires: Editorial Labor, p. $72-73$.

XGarcía Falconí, Ramiro J. “¿Cuál fue el pecado de la CIDH?” en diario El Universo. 12 de junio de 2012. Disponible en: http://www.eluniverso.com/2012/06/13/1/1363/cual-fue-pecado-cidh.html [acceso 2/12/2013].

XI La Doctrina del jurista argentino Carlos Calvo, en 1896, establece que todo extranjero debe realizar sus demandas en los órganos jurisdiccionales del Estado territorial, agotando la vía interna antes de recurrir a reclamaciones por vías diplomáticas. La Doctrina (José) Drago, formulada en 1902 por el entonces canciller argentino, fue una respuesta al anuncio de Estados Unidos de América de no utilizar la doctrina Monroe ante el bloqueo naval a Venezuela por parte de Alemania, Italia y el Reino Unido de Gran Bretaña. Concretamente, establece que ningún Estado extranjero puede hacer uso de la fuerza contra un Estado americano con la finalidad de cobrar una deuda. Por último, la doctrina del, entonces, canciller ecuatoriano Carlos R. Tobar, de 1907, propiciaba el no reconocimiento a cualquier gobierno surgido en violación de las normas constitucionales.

XII García Falconí, Ramiro J. “¿Cuál fue el pecado de la CIDH?” en diario El Universo. 12 de junio de 2012. Disponible en: http://www.eluniverso.com/2012/06/13/1/1363/cual-fue-pecado-cidh.html [acceso 2/12/2013].

XIII La Convención de Viena sobre el Derecho de los Tratados de 1969, en su artículo 53, define a esa norma imperativa de Derecho Internacional General como: "una norma aceptada y reconocida por la comunidad internacional de Estados en su conjunto como norma que no admite acuerdo en contrario y que sólo puede ser modificada por una norma ulterior de Derecho Internacional General que tenga el mismo carácter”.

XIV Pearson, Frederic S. y Rochester, J. Martin (2000). Relaciones Internacionales. Cuarta edición. Bogotá: McGraw-Hill Interamericana Editores, 2000, p.14.

XV Russell, Roberto (2010). "La autonomía y la política mundial: una propuesta para el siglo XXI” en Russell, Roberto y Tokatlián, Juan Gabriel. Autonomía y neutralidad en la globalización. Una realidad contemporánea. Buenos Aires: Capital Intelectual, capítulo 2, p. 103.

${ }^{\mathrm{XVI} K r a s n e r, ~ S t p e h e n ~(1996) ~ " C o m p r o m i s i n g ~ W e s t p h a l i a " ~ e n ~ I n t e r n a t i o n a l ~ S e c u r i t y, ~ v o l .20, ~ n ⿳ ~ 3, ~ i n v i e r n o ~ d e ~}$ 1995-1996, p. 116. Citado en Russell, Roberto (2010).

XVII Russell, Roberto (2010). "La autonomía y la política mundial: una propuesta para el siglo XXI” en Russell, Roberto y Tokatlián, Juan Gabriel. Autonomía y neutralidad en la globalización. Una realidad contemporánea. Buenos Aires: Capital Intelectual, capítulo 2, p. 105-106.

XVIII Russell, Roberto (2010) "La autonomía y la política mundial: una propuesta para el siglo XXI" en Russell, Roberto y Tokatlián, Juan Gabriel. Autonomía y neutralidad en la globalización. Una realidad contemporánea. Buenos Aires: Capital Intelectual, capítulo 2, p. 106-107.

XIX Wendt, Alexander (1999) Social Theory of International Politics. Cambridge: Universidad de Cambridge Press, 1999, p.138. Citado en Russell, Roberto (2010).

Xx Russell, Roberto (2010). "La autonomía y la política mundial: una propuesta para el siglo XXI” en Russell, Roberto y Tokatlián, Juan Gabriel. Autonomía y neutralidad en la globalización. Una realidad contemporánea. Buenos Aires: Capital Intelectual, capítulo 2, p. 107-109. 
XXIXXI Russell, Roberto (2010). "La autonomía y la política mundial: una propuesta para el siglo XXI” en Russell, Roberto y Tokatlián, Juan Gabriel. Autonomía y neutralidad en la globalización. Una realidad contemporánea. Buenos Aires: Capital Intelectual, capítulo 2, p. 113.

XXII Waltz, Kenneth (1988 [1979]). Teoría de la Política Internacional. Buenos Aires: GEL. p.143.

XXIII Waltz, Kenneth (1988 [1979]). Teoría de la Política Internacional. Buenos Aires: GEL., p.143.

XXIV Russell, Roberto (2010). "La autonomía y la política mundial: una propuesta para el siglo XXI” en Russell, Roberto y Tokatlián, Juan Gabriel. Autonomía y neutralidad en la globalización. Una realidad contemporánea. Buenos Aires: Capital Intelectual, capítulo 2, p. 106.

XXv Niemeyer, Theodor (1925). Derecho Internacional Público. Barcelona - Buenos Aires: Editorial Labor, p. 73.

XXVI Asamblea General de las Naciones Unidas.

XXVII Gamio, José María (1995). "El deber de no intervención” en Arbuet-Vignali, Heber y Jiménez de Aréchaga, Eduardo y Puceiro Ripoll, Roberto. Derecho Internacional Público. Tomo II. Montevideo: Fundación de Cultura Universitaria, cap. III, sección V, p. 167.

XXvIII Domínguez Cámpora, Alberto (1947). Derecho Internacional Público. Tomo II. Montevideo: Organización Taquigráfica Medina, p.158.

XXIX Una de las posiciones fue redactada y defendida por Uruguay y expresaba que: "Ningún Estado puede intervenir en los negocios del otro; los casos de excepción a este principio serán determinados por los Estados representados en esta Conferencia, en la oportunidad que juzguen conveniente”. Estados Unidos de América pretendía que se asegurara como excepción la defensa de los ciudadanos de otros países afectados por el Estado territorial. Finalmente, un tercer grupo de países sostuvo la consagración absoluta del principio de no intervención. Domínguez Cámpora, Alberto (1947). Derecho Internacional Público. Tomo II. Montevideo: Organización Taquigráfica Medina, p. 519.

Xxx Domínguez Cámpora, Alberto (1947). Derecho Internacional Público. Tomo II. Montevideo: Organización Taquigráfica Medina, p. 518-519.

XXXI Domínguez Cámpora, Alberto (1947). Derecho Internacional Público. Tomo II. Montevideo: Organización Taquigráfica Medina, p. 515.

XXXII Prohibición del uso y la amenaza de la fuerza; solución pacífica de controversias internacionales; no intervención en asuntos de jurisdicción doméstica de los Estados; cooperación internacional: igualdad de derechos y libre determinación de los pueblos; igualdad soberana de los Estados; buena fe en el cumplimiento de las obligaciones internacionales.

XXXIIIGamio, José María (1995). “El deber de no intervención” en Arbuet-Vignali, Heber y Jiménez de Aréchaga, Eduardo y Puceiro Ripoll, Roberto. Derecho Internacional Público. Tomo II. Montevideo: Fundación de Cultura Universitaria, cap. III, sección V, p. 162-163.

XXXIV El artículo 2 parágrafo 4 establece: "Los Miembros de la Organización, en sus relaciones internacionales, se abstendrán de recurrir a la amenaza o al uso de la fuerza contra la integridad territorial o la independencia política de cualquier Estado, o en cualquier otra forma incompatible con los Propósitos de las Naciones Unidas".

xxxv Gamio, José María (1995). "El deber de no intervención” en Arbuet-Vignali, Heber y Jiménez de Aréchaga, Eduardo y Puceiro Ripoll, Roberto. Derecho Internacional Público. Tomo II. Montevideo: Fundación de Cultura Universitaria, cap. III, sección V, p. 163.

Xxxvi Gamio, José María (1995). "El deber de no intervención” en Arbuet-Vignali, Heber y Jiménez de Aréchaga, Eduardo y Puceiro Ripoll, Roberto. Derecho Internacional Público. Tomo II. Montevideo: Fundación de Cultura Universitaria, cap. III, sección V, p. 163.

XXXVII Si bien todo el capítulo IV, sobre "Derechos y deberes fundamentales" conforma una unidad de la que es posible inferir este principio, son claves los artículos 16, 17, 19, 20 y 21.

XxxvIII Gamio, José María (1995). “El deber de no intervención” en Arbuet-Vignali, Heber y Jiménez de Aréchaga, Eduardo y Puceiro Ripoll, Roberto. Derecho Internacional Público. Tomo II. Montevideo: Fundación de Cultura Universitaria, cap. III, sección V, p. 164-165.

XXXIX El jurista uruguayo recoge dos ejemplos de intervención que no implicaron un ataque armado: el barrido de minas por parte de la marina del Reino Unido de Gran Bretaña en las aguas territoriales de Albania del Canal de Corfú en 1946, con un fallo de la Corte Internacional de Justicia en 1949, y el armado, equipamiento y

Cadernos do Tempo Presente, n. 25, set./out. 2016, p. 31-59| http://www.seer.ufs.br/index.php/tempo 
aprovisionamiento, entre otras acciones, por parte de Estados Unidos de América a las fuerzas armadas de los “contras" enfrentadas con el gobierno de la República de Nicaragua, con un fallo de la Corte Internacional de Justicia en 1986. Gamio, José María. "El deber de no intervención” en Arbuet-Vignali, Heber y Jiménez de Aréchaga, Eduardo y Puceiro Ripoll, Roberto. Derecho Internacional Público. Tomo II. Montevideo: Fundación de Cultura Universitaria, cap. III, sección V, p.166-167.

XL Asamblea General de las Naciones Unidas.

XLI Gamio, José María (1995). "El deber de no intervención” en Arbuet-Vignali, Heber y Jiménez de Aréchaga, Eduardo y Puceiro Ripoll, Roberto. Derecho Internacional Público. Tomo II. Montevideo: Fundación de Cultura Universitaria, cap. III, sección V, p.173-174.

XLII Gamio, José María (1995). "El deber de no intervención” en Arbuet-Vignali, Heber y Jiménez de Aréchaga, Eduardo y Puceiro Ripoll, Roberto. Derecho Internacional Público. Tomo II. Montevideo: Fundación de Cultura Universitaria, cap. III, sección V, p.168-175.

XLIII Gamio, José María (1995). "El deber de no intervención” en Arbuet-Vignali, Heber y Jiménez de Aréchaga, Eduardo y Puceiro Ripoll, Roberto. Derecho Internacional Público. Tomo II. Montevideo: Fundación de Cultura Universitaria, cap. III, sección V, p.175.

XLIV Gros Espiell, Héctor (1994). "Intervención humanitaria y derecho a la asistencia humanitaria” en RamaMontaldo, Manuel, dir. Liber Amicorum. En homenaje al Profesor Eduardo Jiménez de Aréchaga. I. Montevideo: Fundación de Cultura Universitaria, apartado 17, p.308.

XLV Gros Espiell, Héctor (1994). "Intervención humanitaria y derecho a la asistencia humanitaria" en RamaMontaldo, Manuel, dir. Liber Amicorum. En homenaje al Profesor Eduardo Jiménez de Aréchaga. I. Montevideo: Fundación de Cultura Universitaria, apartado 17, p. 309-313.

XLVI Gros Espiell, Héctor (1994). "Intervención humanitaria y derecho a la asistencia humanitaria" en RamaMontaldo, Manuel, dir. Liber Amicorum. En homenaje al Profesor Eduardo Jiménez de Aréchaga. I. Montevideo: Fundación de Cultura Universitaria, apartado 17, p. 313.

XLVII Gros Espiell, Héctor (1994). "Intervención humanitaria y derecho a la asistencia humanitaria" en RamaMontaldo, Manuel, dir. Liber Amicorum. En homenaje al Profesor Eduardo Jiménez de Aréchaga. I. Montevideo: Fundación de Cultura Universitaria, apartado 17, p. 315-317.

XLVIII Abrisketa, Joana (2006) "Intervención humanitaria" en Pérez de Armiño, Karlos, dir. Diccionario de acción humanitaria y cooperación al desarrollo. Universidad del País Vasco. Disponible en: http://www.dicc.hegoa.ehu.es/listar/mostrar/131 [acceso 2/12/2013].

XLIX No obstante, en términos estrictamente jurídicos, la expresión intervención humanitaria supone o la acción militar de uno o más Estados en la jurisdicción de otro con el objetivo de frenar las violaciones graves y masivas a los derechos humanos, o el recurso a la fuerza armada para imponer la ayuda humanitaria a víctimas de los conflictos armados, cuando el Estado soberano territorial impide el paso de la asistencia humanitaria.

L Abrisketa, Joana (2006). "Intervención humanitaria" en Pérez de Armiño, Karlos, dir. Diccionario de acción humanitaria y cooperación al desarrollo. Universidad del País Vasco. Disponible en: http://www.dicc.hegoa.ehu.es/listar/mostrar/131 [acceso 2/12/2013].

Li Estados Unidos de América, Reino Unido de Gran Bretaña, Francia, China y Unión de Repúblicas Soviéticas Socialistas desde 1945 - Rusia a partir de 1991.

LII Abrisketa, Joana (2006). "Intervención humanitaria" en Pérez de Armiño, Karlos, dir. Diccionario de acción humanitaria y cooperación al desarrollo. Universidad del País Vasco. Disponible en: http://www.dicc.hegoa.ehu.es/listar/mostrar/131 [acceso 2/12/2013].

LIII Abrisketa, Joana (2006). "Intervención humanitaria" en Pérez de Armiño, Karlos, dir. Diccionario de acción humanitaria y cooperación al desarrollo. Universidad del País Vasco. Disponible en: http://www.dicc.hegoa.ehu.es/listar/mostrar/131 [acceso 2/12/2013].

LIV Niemeyer, Theodor (1995). Derecho Internacional Público. Barcelona - Buenos Aires: Editorial Labor, p.82.

${ }^{\mathrm{LV}}$ Bermejo, Romualdo (2006). El marco jurídico internacional en materia de uso de la fuerza: ambigüedades y límites. Madrid: Cívitas, 1993. Citado en Abrisketa, Joana.

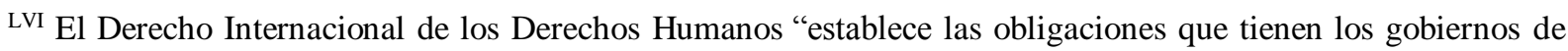
tomar medidas en determinadas situaciones, o de abstenerse de actuar de determinada forma en otras, a fin de promover y proteger los derechos humanos y las libertades fundamentales individuales o colectivas" (Naciones Unidas, 2013: s/n).

Cadernos do Tempo Presente, n. 25, set./out. 2016, p. 31-59| http://www.seer.ufs.br/index.php/tempo 
El Derecho Internacional Humanitario "es un conjunto de normas que, por razones humanitarias, trata de limitar los efectos de los conflictos armados. Protege a las personas que no participan o que ya no participan en los combates y limita los medios y métodos de hacer la guerra". También se lo llama "Derecho de la Guerra" y "Derecho de los Conflictos Armados" (Comité Internacional de la Cruz Roja, 2004:1).

LVII Convención sobre la prohibición del desarrollo, la producción, el almacenaje y el empleo de armas químicas y sobre su destrucción, firmado en 1993 y en vigencia desde 1997. Actualmente cuenta con 190 Estados miembros.

LVIII Russell, Roberto (2010) “La autonomía y la política mundial: una propuesta para el siglo XXI” en Russell, Roberto y Tokatlián, Juan Gabriel. Autonomía y neutralidad en la globalización. Una realidad contemporánea. Buenos Aires: Capital Intelectual, capítulo 2, pp. 101-166.

LIX Gros Espiell, Héctor (1994) "Intervención humanitaria y derecho a la asistencia humanitaria" en RamaMontaldo, Manuel, dir. Liber Amicorum. En homenaje al Profesor Eduardo Jiménez de Aréchaga. I. Montevideo: Fundación de Cultura Universitaria, apartado 17, pp. 299-318.

LX Rusia, China, Cuba, Venezuela y Ecuador intervinieron acusando de politización al propio Consejo y rechazaron cualquier forma de intervención que supusiera alejar la solución del conflicto de la jurisdicción del gobierno de Siria. Fernández Luzuriaga, Wilson (2012) "La inserción internacional de Uruguay: una mirada desde las concepciones neorrealistas de las Relaciones Internacionales" en $6^{\circ}$ Congreso Latinoamericano de Ciencia Política. Quito: Asociación Latinoamericana de Ciencia Política (ALACIP) y FLACSO Sede Ecuador. CD-Rom. ISBN 978-987-20606-7-1.

\section{Bibliografía}

Abrisketa, Joana (2006) "Intervención humanitaria" en Pérez de Armiño, Karlos, dir. Diccionario de acción humanitaria y cooperación al desarrollo. Universidad del País Vasco. Disponible en: http://www.dicc.hegoa.ehu.es/listar/mostrar/131 [acceso 2/12/2013].

Arteaga, Félix (2011) "La Alianza Atlántica tras su cumbre en Lisboa: nuevo concepto, ¿nueva OTAN?" en Real Instituto Elcano. Disponible en: http://www.realinstitutoelcano.org/wps/wcm/connect/d3667000457a2fd3877ec75e7489e10f/ ARI9-

2011 Arteaga Alianza Atlantica Cumbre Lisboa concepto OTAN.pdf?MOD=AJPERES\& CACHEID $=\mathrm{d} 3667000457 \mathrm{a} 2 \mathrm{fd} 3877 \mathrm{ec} 75 \mathrm{e} 7489 \mathrm{e} 10 \mathrm{f}$ [acceso 2/12/2013].

Bermejo, Romualdo (1993). El marco jurídico internacional en materia de uso de la fuerza: ambigüedades y límites. Madrid: Cívitas. Citado en Abrisketa, Joana (2006).

Comité Internacional de la Cruz Roja - Servicio de Asesoramiento en Derecho Internacional Humanitario (2004) ¿Qué es el Derecho Internacional Humanitario? Disponible en: http://www.icrc.org/spa/assets/files/other/dih.es.pdf [acceso 2/12/2013]

Domínguez Cámpora, Alberto (1947) Derecho Internacional Público. Tomo II. Montevideo: Organización Taquigráfica Medina.

Fernández Luzuriaga, Wilson (2012) "La inserción internacional de Uruguay: una mirada desde las concepciones neorrealistas de las Relaciones Internacionales" en $6^{o}$ Congreso Latinoamericano de Ciencia Política. Quito: Asociación Latinoamericana de Ciencia Política (ALACIP) y FLACSO Sede Ecuador. CD-Rom. ISBN 978-987-20606-7-1.

Gamio, José María (1995) "El deber de no intervención” en Arbuet-Vignali, Heber y Jiménez de Aréchaga, Eduardo y Puceiro Ripoll, Roberto. Derecho Internacional Público. Tomo II. Montevideo: Fundación de Cultura Universitaria, cap. III, sección V, pp. 162-167. 
García Falconí, Ramiro J. (2012) “¿Cuál fue el pecado de la CIDH?” en diario El Universo. 12 de junio de 2012. Disponible en: http://www.eluniverso.com/2012/06/13/1/1363/cual-fuepecado-cidh.html [acceso 2/12/2013].

Gros Espiell, Héctor (1994) "Intervención humanitaria y derecho a la asistencia humanitaria" en Rama-Montaldo, Manuel, dir. Liber Amicorum. En homenaje al Profesor Eduardo Jiménez. de Aréchaga. I. Montevideo: Fundación de Cultura Universitaria, apartado 17, pp. 299-318.

Jiménez de Aréchaga, Eduardo (1995) "El deber de no intervención” en Arbuet-Vignali, Heber y Jiménez de Aréchaga, Eduardo y Puceiro Ripoll, Roberto. Derecho Internacional Público. Tomo II. Montevideo: Fundación de Cultura Universitaria, cap. III, sección V, pp. 167-176.

Krasner, Stpehen (1996) "Compromising Westphalia" en International Security, vol.20, $\mathrm{n}^{\circ}$ 3, invierno de 1995-1996, pp. 115-151. Citado en Russell, Roberto (2010).

Naciones Unidas (2013) "Derechos Humanos" en Temas Mundiales. Disponible en: http://www.un.org/es/globalissues/humanrights/ [acceso 2/12/2013].

Niemeyer, Theodor (1925) Derecho Internacional Público. Barcelona - Buenos Aires: Editorial Labor.

Oraá, Jaime (1995) "Derecho Internacional y posibilidades de intervención en situaciones de emergencia” en Convulsión y violencia en el mundo. Seminario de Investigación para la Paz. Zaragoza: Diputación Foral de Aragón y Departamento de Educación y Cultura, pp. 98-114. Citado en Abrisketa, Joana (2006).

Pearson, Frederic S. y Rochester, J. Martin (2000) Relaciones Internacionales. Cuarta edición. Bogotá: McGraw-Hill Interamericana Editores.

Russell, Roberto (2010) "La autonomía y la política mundial: una propuesta para el siglo XXI" en Russell, Roberto y Tokatlián, Juan Gabriel. Autonomía y neutralidad en la globalización. Una realidad contemporánea. Buenos Aires: Capital Intelectual, capítulo 2, pp. 101-166.

Waltz, Kenneth (1988 [1979]) Teoría de la Política Internacional. Buenos Aires: GEL.

Wendt, Alexander (1999) Social Theory of International Politics. Cambridge: Universidad de Cambridge Press. Citado en Russell, Roberto (2010).

\section{Documentos}

Carta de la Organización de Estados Americanos. 1948 (reformada por el: Protocolo de Buenos Aires de 1967, Protocolo de Cartagena de Indias de 1985, Protocolo de Washington de 1992 y Protocolo de Managua de 1993).

Carta de las Naciones Unidas. 1945.

Convención de Viena sobre el Derecho de los Tratados. 1969.

Nuevo Concepto Estratégico. OTAN. 2010.

Nuevo Concepto Estratégico. OTAN. 1999. 
Resolución 2625 (XXV) de la Asamblea General de las Naciones Unidas. Declaración relativa a los principios de Derecho Internacional referentes a las relaciones de amistad y a la cooperación entre los Estados de conformidad a la Carta de las Naciones Unidas. 1970.

Resolución 1514 (XV) de la Asamblea General de las Naciones Unidas. Declaración sobre la concesión de la independencia a los países y pueblos coloniales. 1960.

\section{Comunicados y declaraciones}

Ministerio de Relaciones Exteriores. "Acuerdo sobre armas químicas alcanzado en Ginebra". 16 de septiembre de 2013. Comunicado de prensa.

Ministerio de Relaciones Exteriores. "Comunicado". 22 de agosto de 2013. Fuente: Presidencia de la República.

Ministerio de Relaciones Exteriores. "Comunicado sobre la situación humanitaria en Siria". 2 de agosto de 2013. Fuente: Comunicación e Información Pública del Ministerio de Relaciones Exteriores.

UNASUR. "Declaración del Consejo de Jefas y Jefes de Estado y de Gobierno sobre la situación en la República Árabe de Siria. VII Cumbre Ordinaria. Paramaribo, Surinam. 30 de agosto de 2013".

\section{Otras fuentes}

Programa de Estudios Internacionales. Observatorio de Política Exterior Uruguaya.

Disponible en: http://www.fcs.edu.uy/pagina.php?PagId=819\&CatId=28\&SubCatId=78 [acceso 31/3/2011]. ISSN 1688-7786. 